\title{
Numerical Simulation of Fatigue Performance of Diaphragm of Large-Span Bridge Orthotropic Deck
}

\author{
Hui Li, ${ }^{1}$ Bo Zhao $\mathbb{D}^{1,2}$ and Han $\mathrm{Zhu}^{1,2}$ \\ ${ }^{1}$ School of Civil Engineering, Tianjin University, Tianjin 300072, China \\ ${ }^{2}$ Key Laboratory of Coast Civil Structure Safety, Ministry of Education, Tianjin University, Tianjin 300072, China \\ Correspondence should be addressed to Bo Zhao; zhaobo2010@tju.edu.cn
}

Received 16 March 2018; Revised 20 April 2018; Accepted 2 May 2018; Published 23 October 2018

Academic Editor: Changzhi Wu

Copyright (C) 2018 Hui Li et al. This is an open access article distributed under the Creative Commons Attribution License, which permits unrestricted use, distribution, and reproduction in any medium, provided the original work is properly cited.

Under traffic loads, orthotropic steel bridge slabs suffer from an obvious fatigue problem. In particular, fatigue cracking of diaphragms seriously affects application and development of orthotropic bridge slabs. In the paper, based on cracking status quo of an orthotropic deck diaphragm of a large-span bridge, experimental tests were formulated to test stress distribution states of the diaphragm. The finite element software ABAQUS was used to establish a finite element model of the orthotropic deck diaphragm; numerical simulation was conducted on the basis of the experiments. Simulation results were compared with experimental results, so correctness of the finite element model was verified. Finally, Local Strain Approach (LSA) and Theory of Critical Distance (TCD) were used to conduct life assessment of the orthotropic deck diaphragms, and applicability of two methods was discussed. In this way, a fatigue life assessment method with high accuracy and good operability was provided for fatigue life assessment of orthotropic deck diaphragms.

\section{Introduction}

Design theories and construction technologies for bridge structure have achieved rapid development with the advancement of science and technology. Due to demands for the development of economic and national defense, more and more large-span bridges have been built [1-4]. Featured by large spans and difficult construction, large-span bridge structures have very high requirements for beam body structure types. Featured by high strength, light weight, and high stability, steel box girder structure has become one of the prior beam bodies of these bridges. Orthotropic steel bridge slabs are favorably used for steel box girder structures due to reduced self-weight and high bearing capacity [5-8]. Under traffic loads, orthotropic steel bridge slabs suffer from an obvious fatigue problem. In particular, fatigue cracking of diaphragms seriously affects application and development of orthotropic bridge slabs.

A lot of research has been conducted on fatigue problems of orthotropic steel bridge slabs. Cuninghame described fatigue cracks appearing in three types of structural details of the orthotropic deck of Severn Bridge and made meticulous analysis of cracking reasons [9]. Jen analyzed and demonstrated bearing capacity and fatigue strength of a closedtype trapezoid longitudinal-rib orthotropic steel bridge slab [10]. Tsakopoulos conducted full-scale model fatigue tests on an orthotropic steel deck and obtained stress amplitudes and fatigue lives of all the fatigue rapid-wear parts $[11,12]$. Mizuguchi et al. analyzed reasons for fatigue cracking of top slab longitudinal welding joints of an orthotropic steel bridge slab and pointed out that fatigue performance of welding joints could be enhanced to a certain extent through increasing top slab thickness and reinforcement rib size by $50 \%$ [13]. Miki carried out finite element numerical analysis of top slab longitudinal welding joints of an orthotropic steel bridge slab and proposed that fatigue cracking of the welding joints was caused by small bending rigidity of the top slab [14]. Through experiments, Xiao et al. got to know fatigue performance of U-rib welding joints of an orthotropic plate under a constant stress amplitude and compared the results with the predicted number of fatigue cycles based on the linear elasticity fracture mechanics theory, finding that the fatigue life of U-ribs would decrease greatly when the 
uncompleted welding depth of welding joints reached 2$3 \mathrm{~mm}$ [15]. Battista et al. discussed phenomena and reasons of fatigue cracking on horizontal reinforcement ribs of an orthotropic deck and predicted fatigue life of the bridge through finite element analysis based on previous load forms of the bridge [16]. Xiao et al. established a finite element model for an orthotropic deck and obtained stress distribution of horizontal reinforcement ribs under vehicle loads and then reckoned a design value of fatigue strength according to basic theories of linear elasticity fracture mechanics [17]. Aygül et al. applied three methods to conduct finite element analysis of fatigue life of welding nodes at joints between longitudinal ribs of an orthotropic deck and the diaphragm and compared analysis results with experimental results of full-scale node model fatigue testing [18]. Based on different welding fusion depths and whether arc striking was conducted in advance during welding, Sim et al. carried out full-scale experiments to investigate their effects on fatigue life of connecting welding joints between U-ribs of an orthotropic deck and the bridge slab [19]. Sim and Uang used a notch stress method to conduct finite element simulation of full-scale test specimens. Through parameter analysis, it was found that the fatigue life of connection welding joints between U-ribs of the orthotropic deck and the bridge slab was sensitive to horizontal distribution of external loads [20]. Through on-site experiments, Connor and Fisher determined the antifatigue strength at openings of joints between U-ribs of orthotropic deck and diaphragm and explored analytic solution of the fatigue strength on this basis [21]. Above research focused on fatigue problems of orthotropic steel bridge slabs but failed to discuss stress distribution on different paths of diaphragms and did not conduct deep comparison or analysis of fatigue life assessment methods.

Hence, in the paper, based on cracking status quo of an orthotropic deck diaphragm of a large-span bridge, experimental tests were formulated to test stress distribution states of the diaphragm. The finite element software ABAQUS was used to establish a finite element model of the orthotropic deck diaphragm; numerical simulation was conducted on the basis of the experiments. Simulation results were compared with experimental results, so correctness of the finite element model was verified. Finally, Local Strain Approach (LSA) and Theory of Critical Distance (TCD) were used to conduct life assessment of the orthotropic deck diaphragms, and applicability of two methods was discussed. In this way, a fatigue life assessment method with high accuracy and good operability was provided for fatigue life assessment of orthotropic deck diaphragms.

\section{Assessment Method of Fatigue Life}

General fatigue experiments are not only time- and effortconsuming but also costly. Especially for full-scale models on component or structure levels, fatigue performance could hardly be investigated comprehensively through experiments in general. Hence, numerical analysis becomes the major approach to conducting fatigue assessment of structural components. Through Local Strain Approach (LSA) and Theory of Critical Distance (TCD), the paper conducted life assessment of the structures investigated and discussed applicability of two methods. In this way, a fatigue life assessment method with high accuracy and high operability is provided for fatigue life assessment of orthotropic bridge slabs.

2.1. Local Strain Approach (LSA). Structural fatigue lives investigated in the paper belonged to the magnitude order of $10^{4} \sim 10^{5}$, which could be classified as a middle-low cycle fatigue problem. As for these problems, local elastoplastic states have been formed according to the intensity of the stress, and at initial stage of generation and expansion of cracks, stress indexes may have failed in general. It is generally believed that local strain is a decisive factor for fatigue strength evaluation. Hence, it is applicable to the load scope involved in the paper.

When a local stress value is not bigger than an elasticity limit value, that is, local deformation is elastic deformation, the local strain expression is as follows [22-24]:

$$
\varepsilon=\frac{\sigma_{t}}{E}=\frac{K_{t} \sigma_{n}}{E}=K_{t} \varepsilon_{n} .
$$

In other words, in comparison with a nominal strain value, the local strain value increases by $K_{t}$ folds $\left(K_{t}\right.$ denotes the elastic stress concentration coefficient, that is, the ratio of the local strain value to the nominal strain value is defined as the strain concentration coefficient $K_{t}=\varepsilon / \varepsilon_{n}$ ). During the service process of structure, nominal stress is always lower than yielding stress, but local strain may be higher than yielding strain. Hence, overall force-bearing deformation state of the structure may stay at an elastic deformation stage. A plastic area is formed locally due to plastic strain. Due to the existence of the plastic deformation area, the formula is $K_{\sigma}=\sigma / \sigma_{n}$ at this moment, wherein $K_{\sigma}$ denotes an elastoplastic stress concentration coefficient; $\sigma$ denotes local stress, and $\sigma_{n}$ denotes nominal stress.

Neuber formula involving relations of elastic stress concentration coefficient $K_{t}$, elastoplastic stress concentration coefficient $K_{\sigma}$, and elastoplastic strain concentration coefficient $K_{\varepsilon}$ could be presented by

$$
\begin{aligned}
& K_{t}^{2}=K_{\sigma} K_{\varepsilon}, \\
& \sigma \varepsilon=K_{t}^{2} \sigma_{n} \varepsilon_{n} .
\end{aligned}
$$

Gaps exist under the elastoplastic deformation state, and the cyclic stress-strain relation formula of materials could be represented by

$$
\varepsilon=\frac{\sigma}{E}+\left(\frac{\sigma}{k}\right)^{1 / n^{\prime}}
$$

If the nominal stress $\sigma_{n}$ is known, right parts of Formula (3) would be constants. Hence, changes of $\sigma$ and $\varepsilon$ form a dual-curve form. Through combination of Formula (3) and Formula (4), intersection points between the two curves and the stress-strain curve of materials could be determined. Intersection points of two curves denote local stress value $\sigma$ and local strain value $\varepsilon$, respectively. In other words, stress 
value and strain value of the point with maximum local stress are computed.

As for local stress amplitude and strain amplitude, their relations with nominal stress amplitude and strain amplitude are basically kept unchanged. Based on multiplication theory, Formula (4) could be converted into the following formula:

$$
\frac{\Delta \varepsilon}{2}=\frac{\Delta \sigma}{2 E}+\left(\frac{\Delta \sigma}{2 k}\right)^{1 / n^{\prime}}
$$

Then, fatigue life can be computed according to the Coffin-Manson formula or existing strain- (stress-) fatigue life relations.

2.2. Theory of Critical Distance (TCD). Prediction results of LSA method are always conservative because stress and strain distribution (namely stress and strain gradient effect) at structural stress concentration area is not considered. Fatigue cracks tend to be generated at parts with maximum cyclic stress or strain at first, but initial life prediction of fatigue cracks refers to the life from generation of cracks to their expansion of certain size (including earlier expansion stage of fatigue cracks). Hence, when cracks are generated and start expanding at stress concentration area, crack tips will quickly get deviated from parts with maximum stress and strain. In other words, after generation and expansion of local cracks, contribution made by maximum cyclic stress and strain to subsequent crack expansion would be reduced. Hence, it is conservative to predict fatigue crack initial life with maximum cyclic stress or strain in stress concentration areas.

Neuber and Peterson proposed fatigue limit (or fatigue strength) prediction idea with consideration of local stress distribution. Neuber proposed that the average value of elastic stress within a certain distance from a local area should be taken as valid stress. Peterson believed that stress at a point with a certain distance from the local area should be taken as valid stress. With above two ideas as the development foundation, Taylor conducted deep research, and formed a uniform TCD. Specifically, the method which takes the average value of elastic stress within a certain distance from a local area as the valid stress was developed into a "line method." The method which takes stress at a point with certain distance from the local area as valid stress was developed into "point method." The method which takes average stress on the area within a certain distance from the local area as valid stress was developed into "area method." TCD was successively applied to research of local structure fatigue limit prediction, static strength prediction, etc. Good results were achieved.

At present, TCD has achieved continuous development and perfection. The initial "point method" has been developed into "volume method" of three-dimensional space through the "line method" of one-dimensional space and two-dimensional space. With simple application, point method and line method are commonly used; area method and volume method with high computation complexity are not applied frequently. Basic theories of point method, line method, and area method are shown in Figure 1. Computation methods of the average stress $\sigma_{\mathrm{av}}$ are shown as follows.

$$
\begin{aligned}
& \text { Point method : } \sigma_{\mathrm{av}}=\sigma_{1}\left(r=\frac{L_{0}}{2}, \theta=0\right) \text {, } \\
& \text { Line method : } \sigma_{\mathrm{av}}=\frac{1}{2 L_{0}} \int_{0}^{2 L_{0}} \sigma_{1}(r, \theta=0) d r \text {, } \\
& \text { Area method : } \sigma_{\mathrm{av}}=\frac{1}{1.1 \pi L_{0}^{2}} \int_{\pi / 2}^{\pi / 2} \int_{0}^{L_{0}} \sigma_{1}(r, \theta) r d r d \theta \text {, } \\
& \text { Volume method : } \sigma_{\mathrm{av}}=\frac{3}{2 \pi\left(1.54 L_{0}\right)^{3}} \cdot \int_{0}^{2 \pi} \int_{0}^{\pi / 2} \int_{0}^{1.54 L} \\
& \text { - } \sigma_{1}(r, \theta, \varphi) r^{2} \sin \theta d r d \theta d \varphi \text {. }
\end{aligned}
$$

In the above formulas, the critical distance parameter $L_{0}$ is determined by experiments and can also be given by short crack theory of EI Haddad as follows:

$$
L_{0}=\frac{1}{\pi}\left(\frac{\Delta K_{\mathrm{th}}}{\Delta \sigma_{\mathrm{f}}}\right)^{2} .
$$

In this formula, $\Delta K_{\text {th }}$ denotes a threshold value of stress strength factor amplitude of the material; $\Delta \sigma_{\mathrm{f}}$ denotes fatigue limit and can be equivalent to constant amplitude fatigue limit or variant amplitude fatigue limit in a pure material $S-N$ curve.

Fatigue limit $\Delta \sigma_{\mathrm{f}}$ is a parameter correlated with designed life. For example, in engineering, the stress amplitude corresponding to 2 million-cycle fatigue life is often used as the fatigue limit. Hence, critical distance parameter $L_{0}$ also varies with the set fatigue life $N_{\mathrm{f}}$. During fatigue life estimation of the material, the critical distance $L_{0}$ and the fatigue life $N_{\mathrm{f}}$ are assumed to have the following relation at present:

$$
L_{0}=A\left(N_{\mathrm{f}}\right)^{B} .
$$

In this formula, $A$ and $B$ denote material constants, which are generally determined by critical distances corresponding to material static strength and fatigue limit. Static strength failure of the material generated under static force stretching is deemed as the failure happening under $1 / 4$ cyclic loading, namely $N_{\mathrm{f}}=1 / 4$. At this moment, critical distance $L_{0 \mathrm{~b}}$ corresponding to the material static strength is as follows:

$$
\begin{aligned}
& L_{0 \mathrm{~b}}=A\left(\frac{1}{4}\right)^{B}=\frac{1}{\pi}\left(\frac{K_{\mathrm{IC}}}{\sigma_{u}}\right)^{2}, \\
& L_{0 L}=A\left(2 \times 10^{6}\right)^{B}=\frac{1}{\pi}\left(\frac{\Delta K_{\mathrm{th}}}{\Delta \sigma_{\mathrm{f}}}\right)^{2} .
\end{aligned}
$$

By Formula (13), material constants $A$ and $B$ can be obtained. On this basis, the quantitative wherein between critical distance $L_{0}$ and fatigue life $N_{\mathrm{f}}$ can be obtained. In this way, structural life can be obtained by any kind of TCD method in combination with Formula (11) and the $S$ - $N$ relation curve. 


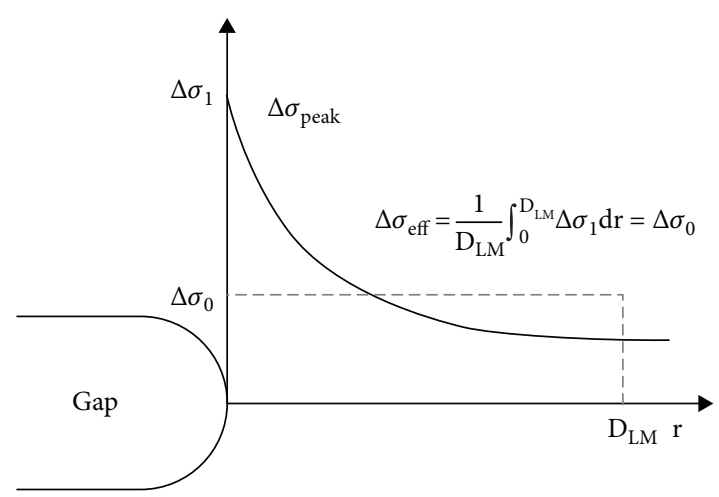

(a)

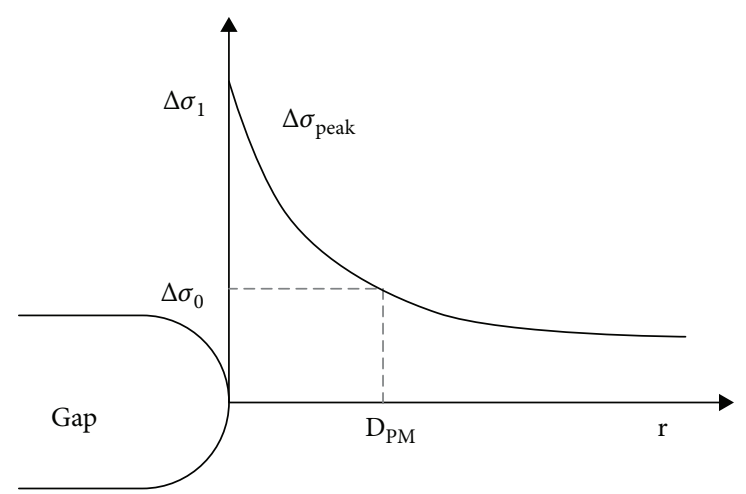

(b)

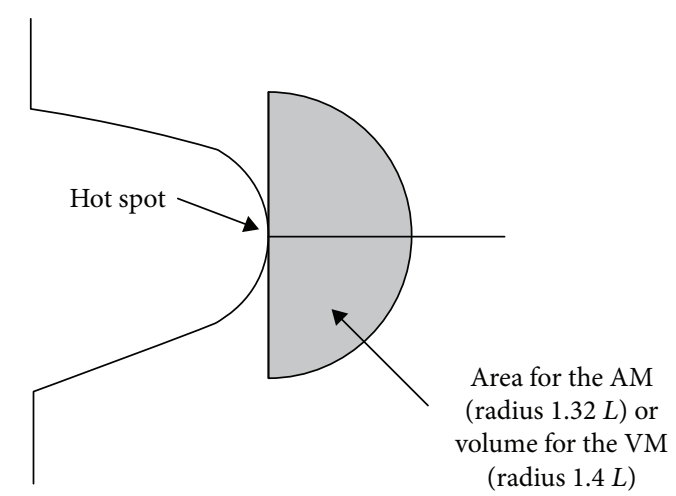

(c)

Figure 1: Common TCD diagrams. (a) Line method (LM). (b) Point method (PM). (c) Area method (AM) and volume method (VM).

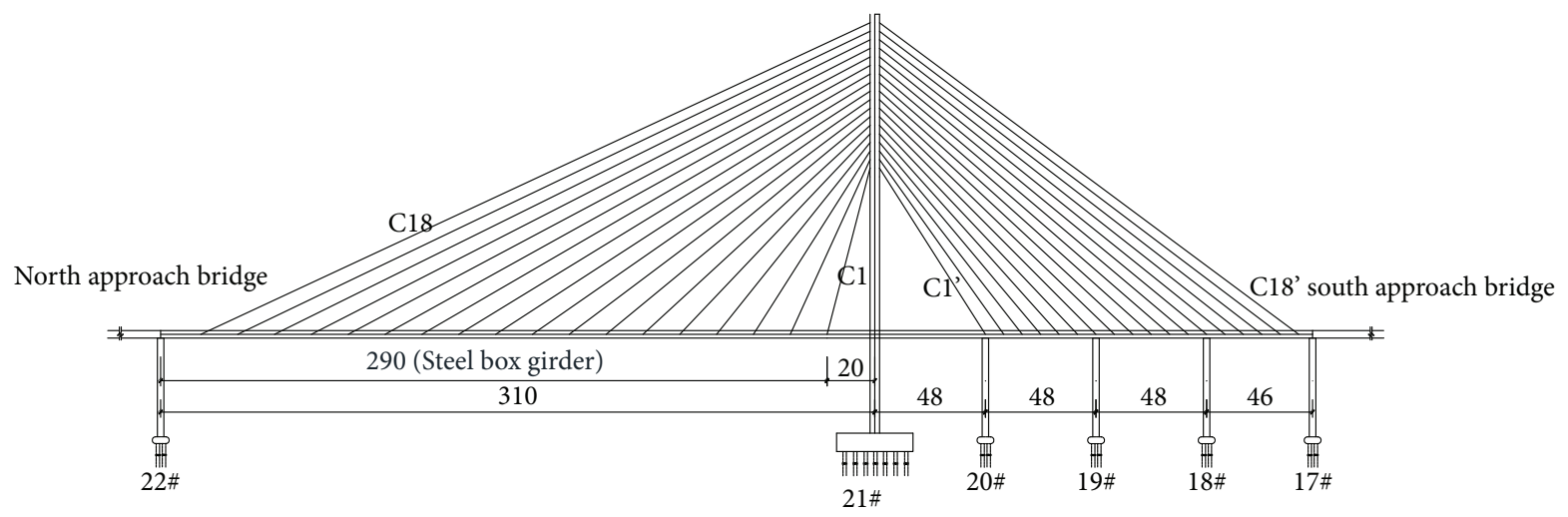

FIGURE 2: Structural diagram of large-span bridge $(\mathrm{m})$.

\section{Finite Element Model of Large-Span Bridge and Computation Results}

The bridge crossing the North-South direction is the key to the research. As an important traffic line ensuring normal running of port logistics center, the bridge bears passing of a lot of heavy-type trunks. With forty-one spans, the bridge is $2033 \mathrm{~m}$ long, as shown in Figure 2. The main bridge is a concrete hybrid-beam single-tower cable-stayed bridge, with main span of $310 \mathrm{~m}$, side span of $190 \mathrm{~m}$, and total length of $500 \mathrm{~m}$. Three auxiliary piers are set on the side span, which is divided into four spans. Span combination is $(3 \times 48+46) \mathrm{m}$.
Prestress concrete box girders are located on the main span within $20 \mathrm{~m}$ away from the main tower. Steel box girders are located on the rest main span of $290 \mathrm{~m}$. All the side spans are prestress concrete box girders. General cross section of the main beam is shown in Figure 3. The main steel beam is made of $\mathrm{Q} 345 \mathrm{qD}$, with beam height of $3 \mathrm{~m}$, box width of $23 \mathrm{~m}$ (excluding tuyere), stage cable midrange of $22.3 \mathrm{~m}$, side box width of $9.077 \mathrm{~m}$, middle horizontalbeam width of $6.0 \mathrm{~m}$, and $1.5 \%$ of horizontal slopes set on the deck.

3.1. Establishment of Finite Element Model. In order to define characteristics of stress distribution on diaphragms on an 


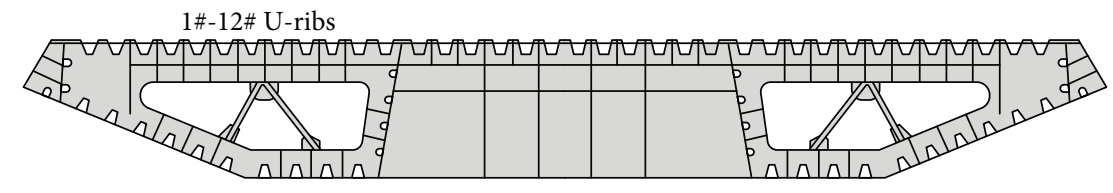

FIgURE 3: Standard cross section of main beam of large-span bridge.

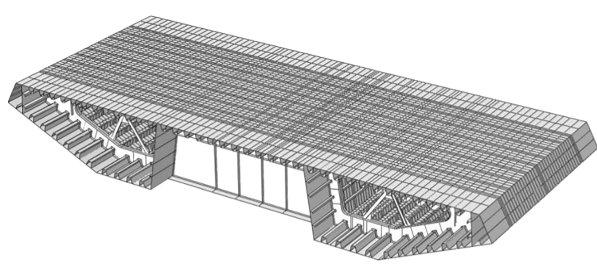

(a)

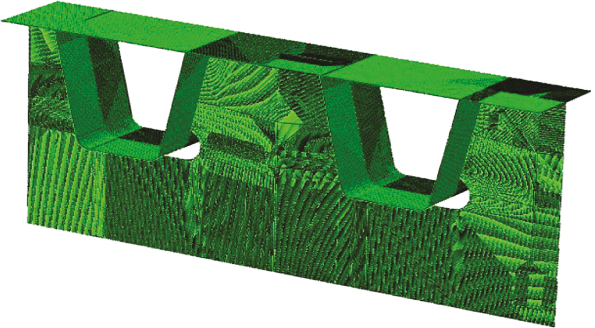

(b)

Figure 4: Finite element model of orthotropic steel box girder of bridge. (a) Finite element model of orthotropic steel box girder. (b) Local submodel of diaphragm.

orthotropic deck under vehicle loads, 3 main beam sections near the horizontal beam were selected. ABAQUS software [25-27] was used to establish a finite element model of the orthotropic steel box girder. Vehicle loads were applied for elastoplastic analysis. Firm connection of two ends of the steel box girder was set as the boundary condition. The constitutive model parameters of steel material were measured. Poisson's ratio was 0.3 . In order to conduct refinement analysis of force bearing of diaphragms near joints between U-ribs and diaphragms, structural details of joints between U-ribs and diaphragms were selected. With submodel technologies, a local submodel of diaphragm was established. S4R shell units were adopted for the finite element model of orthotropic steel box girder and the local submodel of diaphragm. The dimension of elements in the integral model is $50 \mathrm{~mm} \times 50 \mathrm{~mm}$. The number of elements is 494,092 and the number of nodes is 485,774 . By contrast, the dimension of elements in the submodel is $2 \mathrm{~mm} \times 2 \mathrm{~mm}$. The number of elements is 835,637 and the number of nodes is 840,796 . The mesh of elements was refined in the submodel to achieve a more realistic stress distribution. Effects of welding joints were not considered. The finite element model is shown in Figure 4.

3.2. Experimental Verification of Finite Element Model. In order to investigate stress distribution at the cut-outs in diaphragms under U-ribs and at welding positions between U-ribs and diaphragms under wheel loads and verify correctness of the numerical models, local static loading experiment and dynamic loading experiment were conducted for the bridge. Fatigue cracks did not appear at selected testing positions in the real bridge. Hence, force-bearing characteristics of the original bridge slab can be reflected. Twenty-two stress measurement points were arranged, among which twenty were one-way strain gages and two were three-way strain gages. Four one-way strain gages were mounted annularly at downstream lateral cut-outs of 10\# U-rib. Four one-way strain gages and one three-way strain gage were

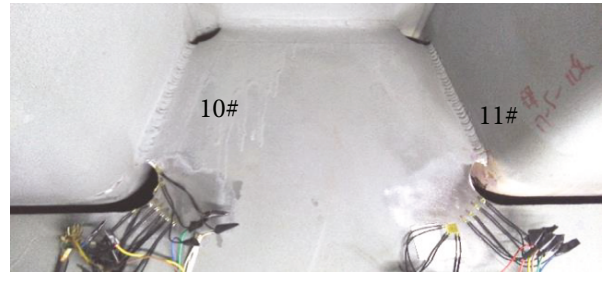

FIgURE 5: On-site layout diagram of experimental strain gages.

mounted along the radial direction of $45^{\circ}$. Four one-way strain gages were mounted annularly at upstream lateral cut-outs of 10\# U-rib. Four one-way strain gages were mounted along the radial direction of $45^{\circ}$. Four one-way strain gages and one three-way strain gage were mounted along the radial direction of $45^{\circ}$ at downstream lateral cut-outs of $11 \# \mathrm{U}$-rib. On-site layout of strain gages is shown in Figure 5. The selected vehicle load had three shafts. Front wheel axle load was $100 \mathrm{kN}$. Axle load of two rear wheels was equally $190 \mathrm{kN}$. Ground size of front wheel was $300 \times 200 \mathrm{~mm}$, and ground size of rear wheels was $600 \times 200 \mathrm{~mm}$. Rear wheels of the vehicle directly acted on 10\# and 11\# U-ribs, as shown in Figure 6. Six eworking conditions were selected in the experiment. Under each working condition, horizontal positions of wheels were moved by $1 \mathrm{~m}$ towards the main beam center. Details are shown in Table 1.

Experimental results were compared with finite element computation results, as shown in Figure 7. It shows that finite element results approached practically measured results. Under working condition 1 and working condition 2, finite element results were larger than measured values. The reason is that the streamline steel box girder of the bridge is of high rigidity, and loads would be diffused far when wheels acted on a diaphragm; however, during finite element computation, three diaphragms were extracted and rigid supporting existed on two sides, so load transmission scope was limited. Secondly, the pavement on the real bridge already had certain 


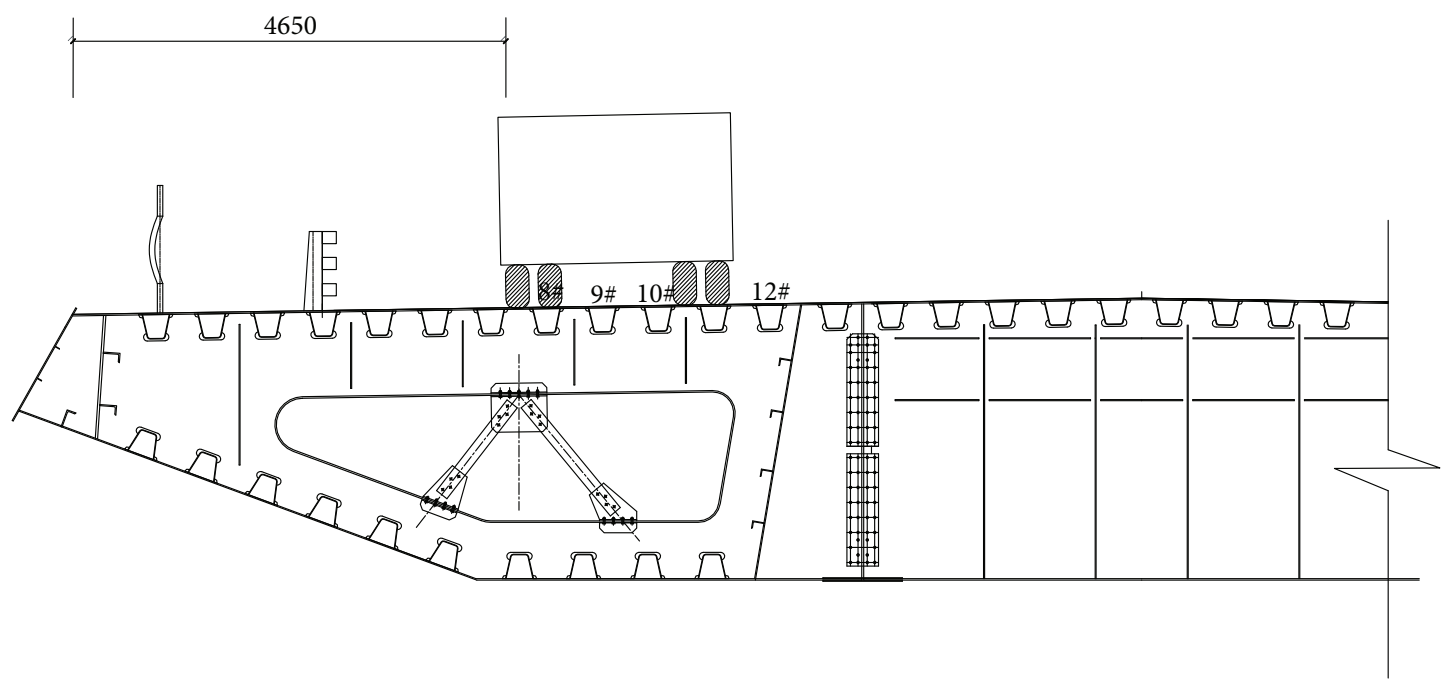

FIgURe 6: Acting positions of experimental vehicle loads (mm).

TABLE 1: Summary of working condition.

\begin{tabular}{lcccccc}
\hline Working condition & 1 & 2 & 3 & 4 & 5 & 6 \\
Distance $(\mathrm{mm})$ & 4650 & 5650 & 6650 & 7650 & 8650 & 9650 \\
\hline
\end{tabular}

rigidity and could bear force together with the bridge slab, but the contribution of pavement layers was not considered in finite element computation. Hence, under these two working conditions, finite element computation values were obviously larger than actually measured values. Under working conditions 3-6, the vehicle was already far from 10\# and $11 \#$ U-ribs, and measured values were larger than finite element computation values. The reason is that transmission scope of loads in the real bridge was large under effects of the pavement layer, but transmission scope of loads in the finite element model was small and concentrated.

3.3. Mises Stress Distribution of Diaphragms. Under wheel loads, diaphragms would easily have local stress concentration at overwelding holes and the cut-outs in diaphragms under U-ribs. In order to analyze characteristics of stress distribution on diaphragms under six working conditions, a diaphragm local submodel was used to analyze stress size at diaphragm parts with easy stress concentration, as shown in Figure 8. Under working condition 1, wheels directly acted on 11\# U-rib and steel top place between 10\# U-rib and 11\# U-rib. Maximum stress appeared at the cut-out in the diaphragm under 11\# U-rib near 10\# U-rib. Mises stress already reached $123 \mathrm{MPa}$. Far from this place, Mises stress rapidly attenuated to that under $58 \mathrm{MPa}$. Under working condition 2 , wheels acted on two sides of 10\# and 11\# U-ribs. At this moment, Mises stress at the cut-outs in the diaphragm under $10 \#$ and 11\# U-ribs was already large and reached $118 \mathrm{MPa}$. 11 \# U-rib was close to the box girder web, so two U-ribs suffered obvious distortion. Under working condition 3, wheels acted right above 11\# U-rib. At this moment, two wheels of the vehicle stretched over the steel box girder web. Rigidity of the steel girder web was high, so force distributed on the
U-rib was small. At this moment, Mises stress at the cutout in diaphragm under 11\# U-rib near 10\# U-rib was about $80 \mathrm{MPa}$. Under working conditions $4-6$, acting positions of vehicle loads were far from 10\# and 11\# U-ribs. Mises stress of $10 \#$ and 11\# U-ribs was obviously reduced. Under working conditions 4-6, the maximum Mises stress was $16.9 \mathrm{MPa}$, $22.2 \mathrm{MPa}$, and $21.8 \mathrm{MPa}$, respectively. Under the three working conditions, U-rib deformation manifested obvious clockwise distortion.

3.4. Main Stress Distribution at Cut-Outs in Diaphragms under U-Ribs. Analysis results show that obvious stress concentration appeared at cut-outs in diaphragms under U-ribs. In order to analyze stress distribution at cut-outs in diaphragms, main stress along the edges of cut-outs under six working conditions was extracted. Extraction paths are shown in Figure 9. $\mathrm{S}$ denotes a path starting position, and $\mathrm{E}$ denotes an ending position. Total length of paths was $95 \mathrm{~m}$. As for path 1 and path 2, stress was large under working condition 1 and working condition 2. As for path 3 and path 4, stress was large under working conditions 1,2 , and 3. Stress distribution along path 1 , path 2 , path 3 , and path 4 under 6 working conditions is shown in Figure 10. Along the paths, stress distribution approached an upward raised parabolic pattern. Along path 1 and path 2, stress peaks appeared at the position $60 \mathrm{~mm}$ away from the path starting point. The included angle between the line connecting the position and the center of the cut-out and the horizontal plane was about $20^{\circ}$. Along path 3 and path 4 , stress peaks appeared at different positions under different working conditions. Along path 3, peak value appeared at the position $50 \mathrm{~mm}$ away from the path starting point under working condition 1 , and the stress already reached $118 \mathrm{MPa}$. Under working condition 2, the peak stress of $97 \mathrm{MPa}$ appeared at the position $60 \mathrm{~mm}$ away from the path starting point. Under working condition 3, the peak value of $87 \mathrm{MPa}$ appeared at the position $40 \mathrm{~mm}$ away from the path starting point. Along path 4, stress distribution was shaped like sine curves under working conditions 1 and 3 . Under working conditions 1, 2, 


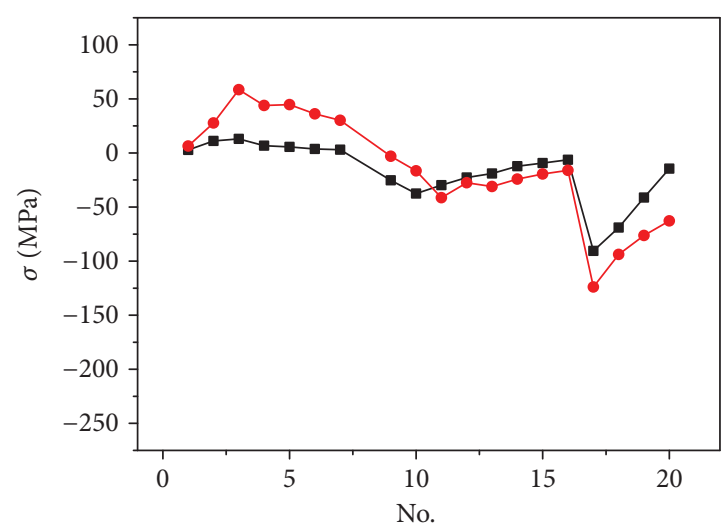

- Measured results of working condition 1

- Finite element model results of working condition 1

(a)

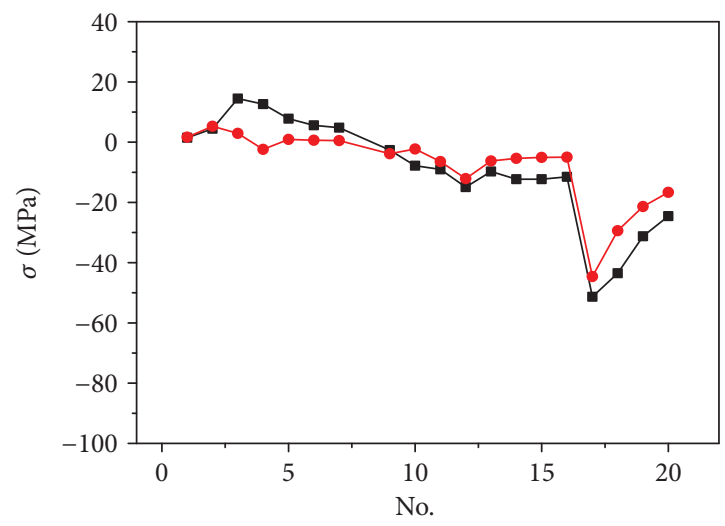

- Measured results of working condition 3

$\rightarrow$ Finite element model results of working condition 3

(c)

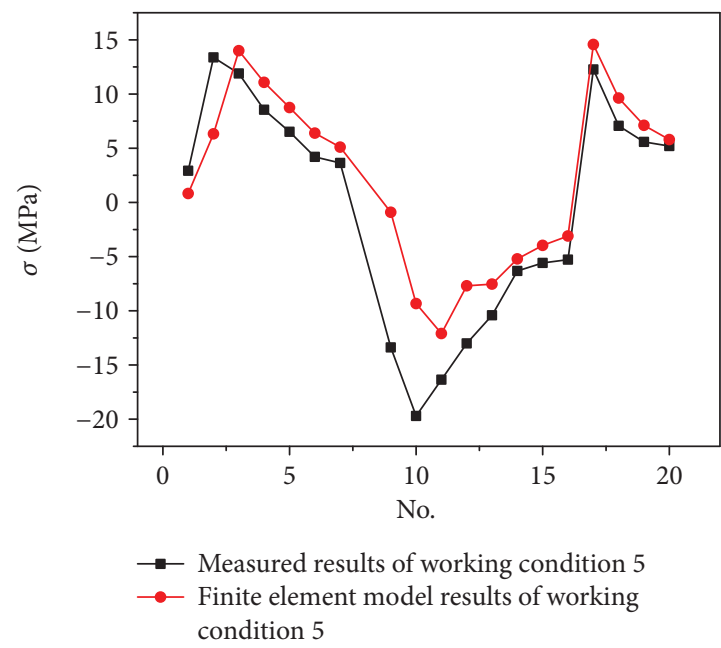

(e)

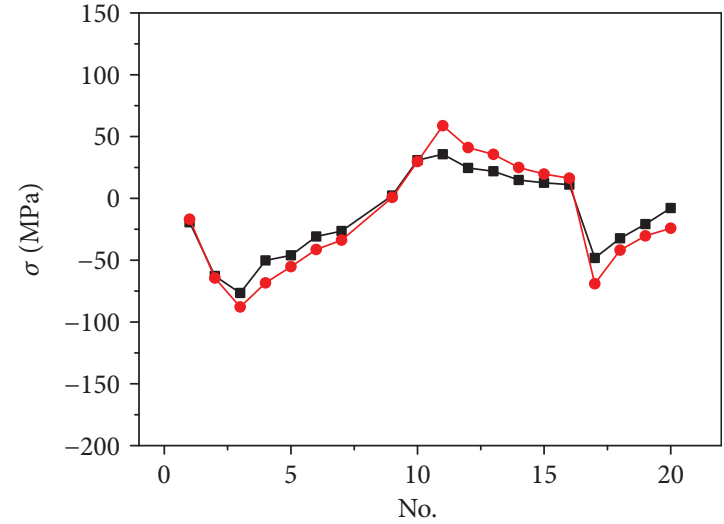

- Measured results of working condition 2

$\rightarrow$ Finite element model results of working condition 2

(b)

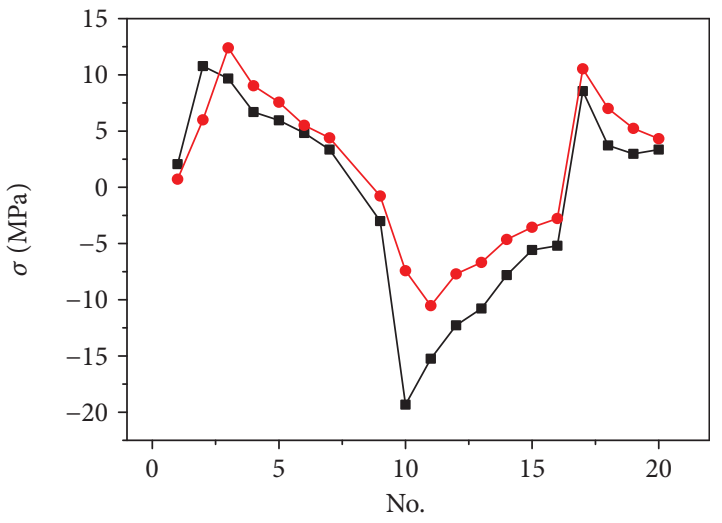

- Measured results of working condition 4

$\rightarrow$ Finite element model results of working condition 4

(d)

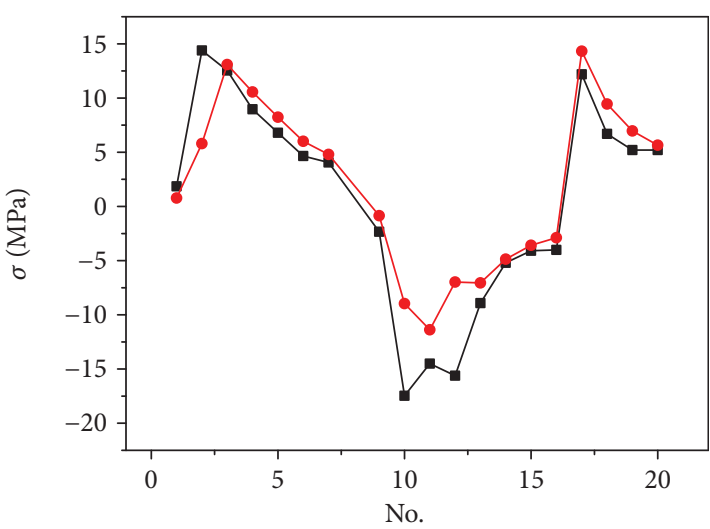

- Measured results of working condition 6

$\rightarrow$ Finite element model results of working condition 6

(f)

FIGURE 7: Comparison of numerical simulation and experimental testing. (a) Working condition 1. (b) Working condition 2. (c) Working condition 3. (d) Working condition 4. (e) Working condition 5. (f) Working condition 6. 
$S$, mises

SNEF, (fraction $=-1.0$ )

(Avg: 75\%)

$\begin{aligned} & +1.725 \mathrm{e}+02 \\ & +1.582 \mathrm{e}+02 \\ & +1.438 \mathrm{e}+02 \\ & +1.295 \mathrm{e}+02 \\ & +1.151 \mathrm{e}+02 \\ & +1.008 \mathrm{e}+02 \\ & +8.640 \mathrm{e}+02 \\ & +7.210 \mathrm{e}+02 \\ & +5.770 \mathrm{e}+02 \\ & +4.333 \mathrm{e}+02 \\ & +2.897 \mathrm{e}+02 \\ & +1.462 \mathrm{e}+02 \\ & +2.660 \mathrm{e}-01\end{aligned}$

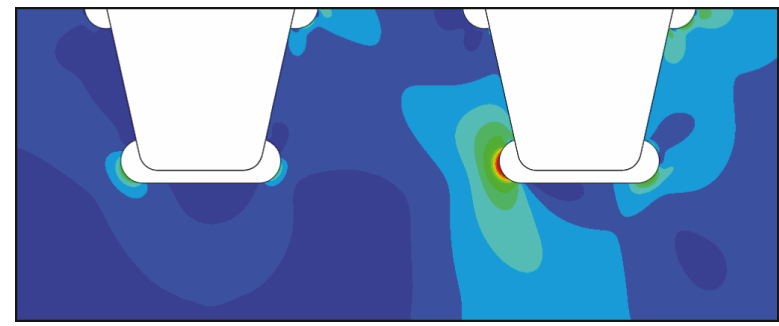

(a)

$S$, mises

SNEF, (fraction $=-1.0$ )

(Avg: $75 \%$ )
$+1.175 \mathrm{e}+02$
$+1.077 \mathrm{e}+02$
$+9.790 \mathrm{e}+02$
$+8.815 \mathrm{e}+02$
$+7.835 \mathrm{e}+02$
$+6.855 \mathrm{e}+02$
$+5.875 \mathrm{e}+02$
$+4.898 \mathrm{e}+02$
$+3.920 \mathrm{e}+02$
$+2.941 \mathrm{e}+02$
$+1.963 \mathrm{e}+02$
$+9.840 \mathrm{e}+02$
$+5.405 \mathrm{e}-02$

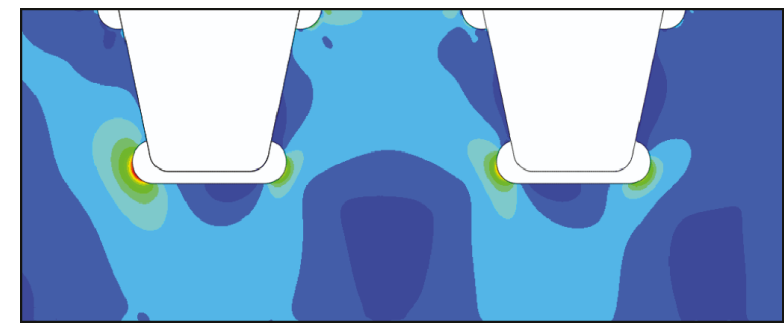

(b)

$\mathrm{S}$, mises

SNEF, (fraction $=-1.0$ )

(Avg: 75\%)
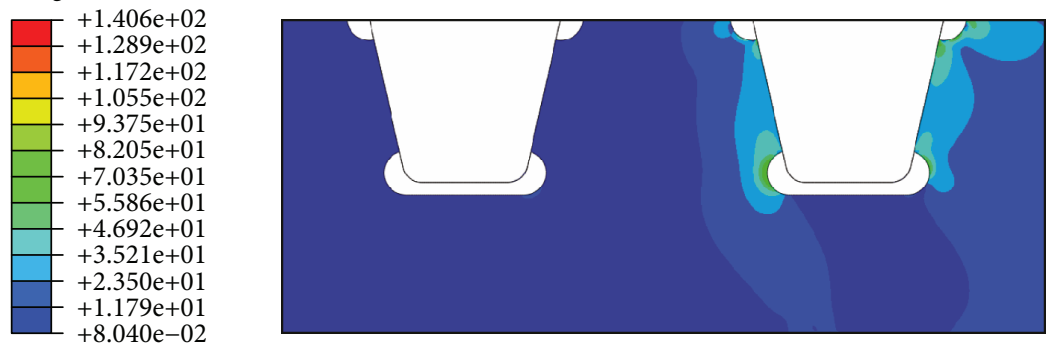

(c)

$\mathrm{S}$, mises

SNEF, (fraction $=-1.0$ )

(Avg: 75\%)

$\begin{aligned} \square & +1.687 \mathrm{e}+01 \\ & +1.546 \mathrm{e}+01 \\ & +1.406 \mathrm{e}+01 \\ & +1.265 \mathrm{e}+01 \\ & +1.125 \mathrm{e}+00 \\ & +9.846 \mathrm{e}+00 \\ & +8.443 \mathrm{e}+00 \\ & +7.039 \mathrm{e}+00 \\ & +5.635 \mathrm{e}+00 \\ & +4.231 \mathrm{e}+00 \\ & +2.827 \mathrm{e}+00 \\ & +1.423 \mathrm{e}+00 \\ & +1.950 \mathrm{e}-02\end{aligned}$

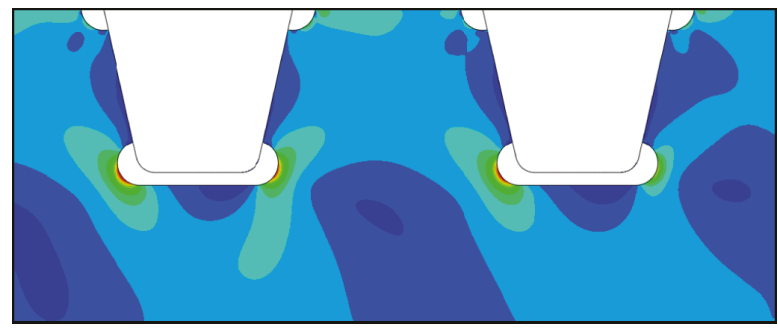

(d)

Figure 8: Continued. 
S, mises

SNEF, (fraction $=-1.0)$

(Avg: $75 \%$ )
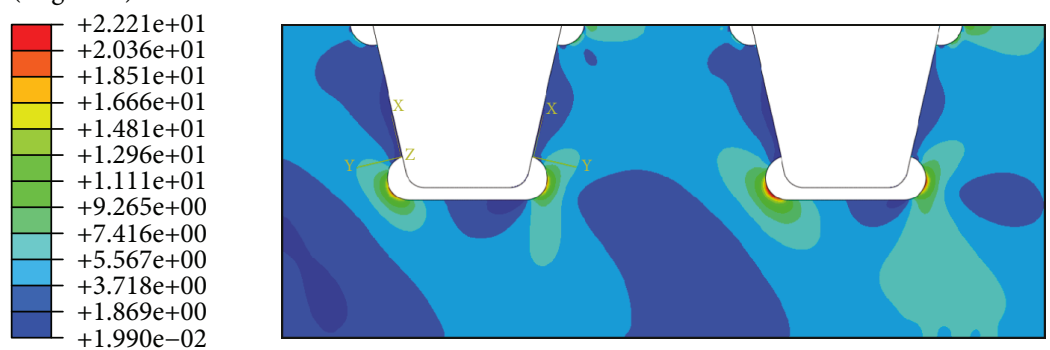

(e)
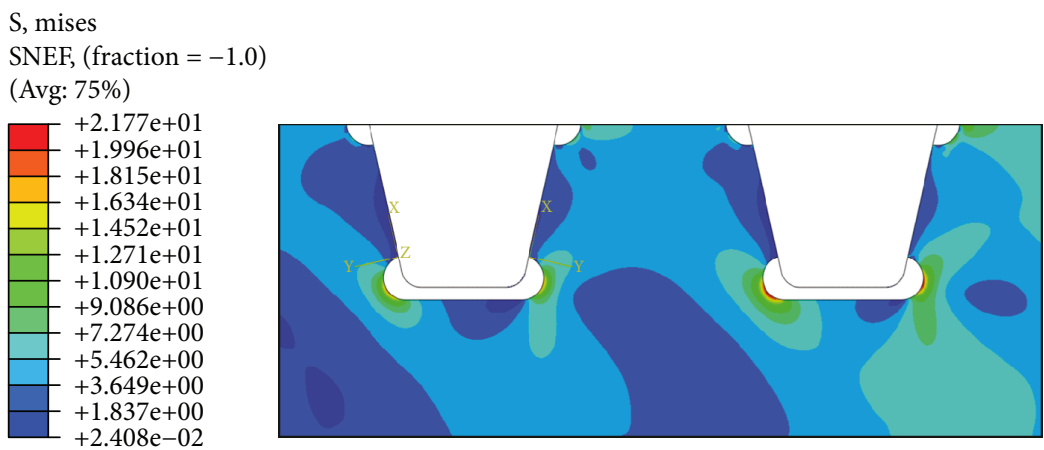

(f)

FIGURE 8: Comparison of Mises stress on diaphragm under 6 working conditions. (a) Mises stress on diaphragm under working condition 1. (b) Mises stress on diaphragm under working condition 2. (c) Mises stress on diaphragm under working condition 3. (d) Mises stress on diaphragm under working condition 4. (e) Mises stress on diaphragm under working condition 5. (f) Mises stress on diaphragm under working condition 6 .

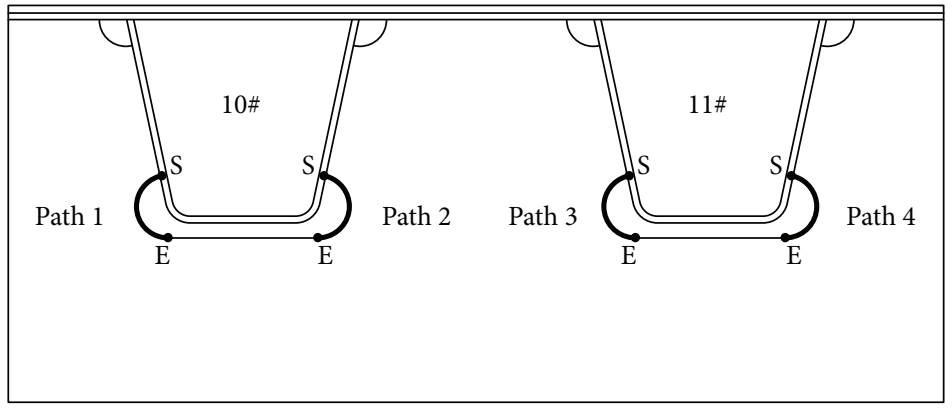

Figure 9: Stress extraction paths 1-4 (S: path starting; E: path ending).

and 3, peak stress values were $99 \mathrm{MPa}, 79 \mathrm{MPa}$, and $67 \mathrm{MPa}$, respectively, and the distances between peak stress position and the path starting point were $80 \mathrm{~mm}, 70 \mathrm{~mm}$, and $30 \mathrm{~mm}$.

Meanwhile, in order to analyze stress distribution at positions near cut-outs in diaphragms under U-ribs, with different distances from the edges of cut-outs, stress along the following eight paths on the diaphragm was extracted. Included angle between paths 5-8 and the horizontal plane was $20^{\circ}$, and the length of paths $5-8$ was $60 \mathrm{~mm}$. Paths $13-$ 16 were parallel with the horizontal plane with length of $60 \mathrm{~mm}$, as shown in Figure 11. It is shown in Figure 12 that stress along the paths reached the maximum value on the edges of cut-outs; stress gradually attenuated with the increase of distance from the edges of cut-outs; when the distance was $20 \mathrm{~mm}$, the attenuation amount was already very significant and reached about $60 \%$; with the continuous increase of distance, the attenuation speed decreased gradually and the stress tended to be unchanged. It is shown in Figure 13 that stress distribution along paths 13-16 has the same rules with that along paths 5-8. As for path 15 , stress at the path starting position already reached $117 \mathrm{MPa}$ under working condition 1 . As for path 16, stress suffered alternate pulling-pressing phenomena under different working conditions. For example, tension stress appeared under working conditions 1 and 2; compression stress appeared under working conditions 3-6. Horizontal positions were random to a certain extent when the vehicle passed. Hence, when the 


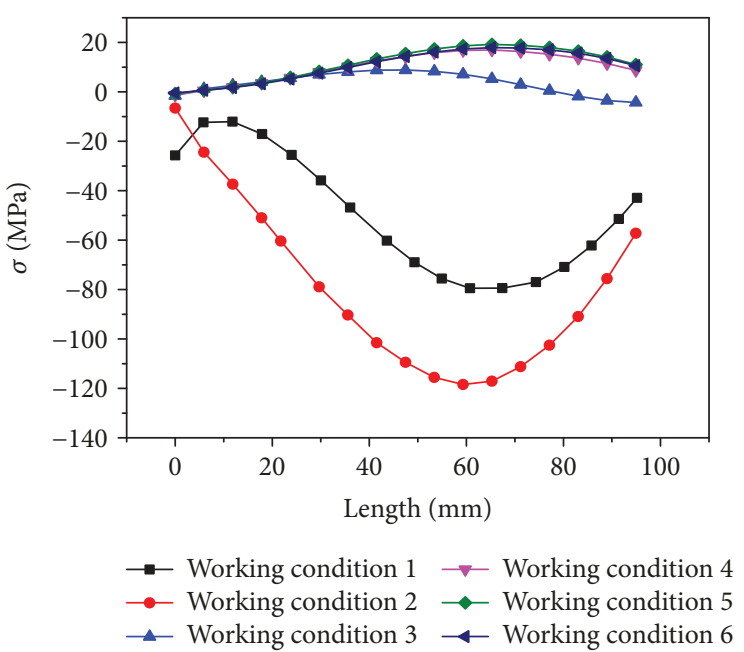

(a)

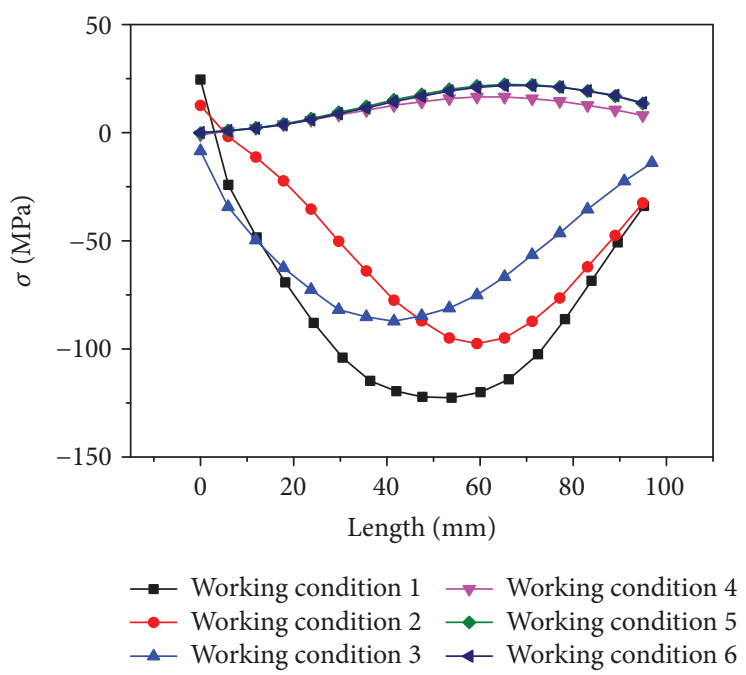

(c)

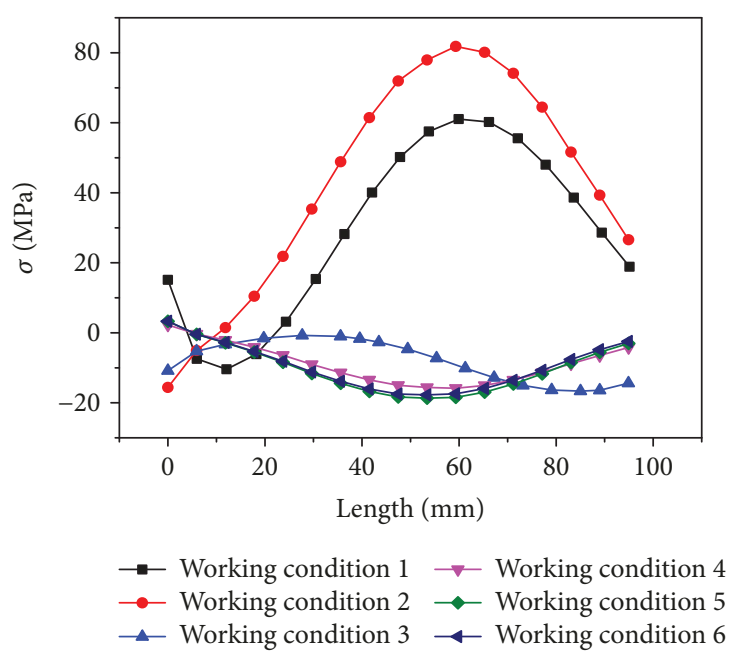

(b)

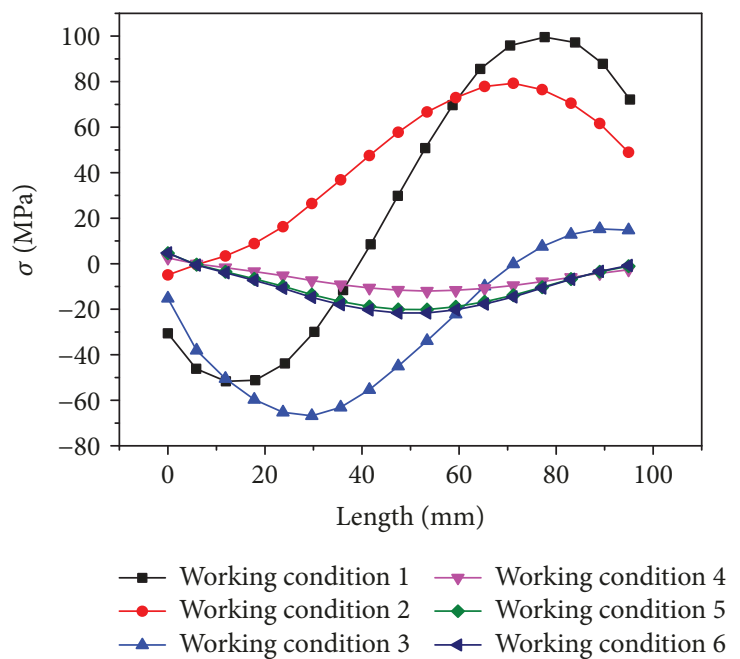

(d)

Figure 10: Stress distribution on the edges of cut-outs in diaphragms under U-ribs. (a) Path 1. (b) Path 2. (c) Path 3. (d) Path 4.

vehicle passed by different horizontal positions, a lot of stress cycles and large stress amplitude would be generated here. As a result, fatigue cracking took place.

\subsection{Main Stress Distribution at Welding Joints of U-Rib and} Diaphragm. Welding position of U-rib and diaphragm is one of the structural details which often suffer from fatigue cracks in real bridges. In order to investigate stress distribution at the structural detail under wheel loads, four paths as shown in Figure 14 were selected. Stress distribution in the direction perpendicular to the paths under six working conditions was extracted. Results are shown in Figure 15. Path length was $182 \mathrm{~mm}$. It is shown in Figure 15 that stress on the paths was small and approached $0 \mathrm{MPa}$. Stress concentration appeared at positions near the cutouts in diaphragms under U-ribs and overwelding holes located at joints between U-rib and top plate. Stress increased suddenly. Length of the sudden stress change scope was about $10 \mathrm{~mm}$. As for path 12, obvious sudden change of stress took place at the position near the cut- out in the diaphragm under working condition 1 and the stress reached $73 \mathrm{MPa}$.

\section{Fatigue Life Assessment of Full-Scale Test Specimens of Orthotropic Bridge Slab}

4.1. Establishment of Numerical Model. ABAQUS was used to conduct numerical analysis of U-ribs of the orthotropic bridge slab and the rib plate connecting diaphragm. Component sizes and boundary conditions adopted were consistent with the experiment. Geometric models of the fatigue test specimens can be handled and simplified in software. The paper intends to conduct fatigue life assessment with LSA and TCD, so setting of a material constitutive model should be noted during analysis. As for LSA, elastoplastic stress and strain states near the local gap should be taken into account, so an elastoplastic constitutive model should be adopted. Measured values of points on the steel constitutive stress-strain curves were adopted. Poisson's ratio was 0.3. As for TCD, which is an analysis method based on linear 


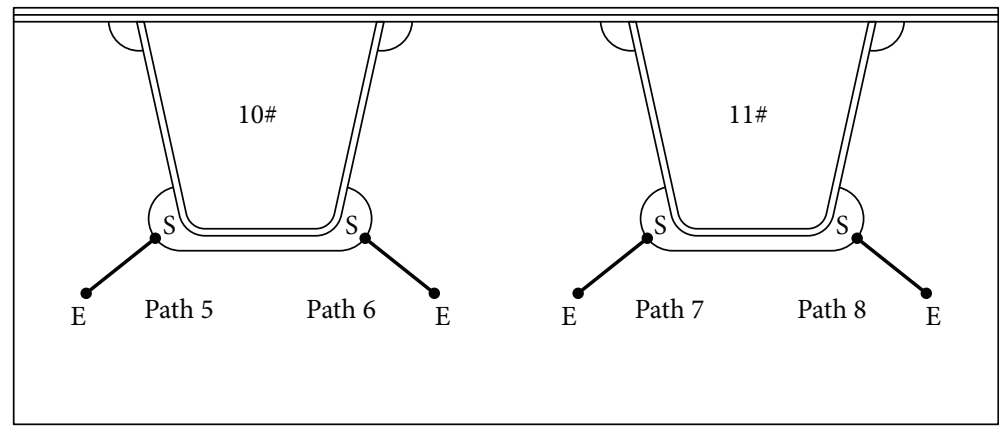

(a)

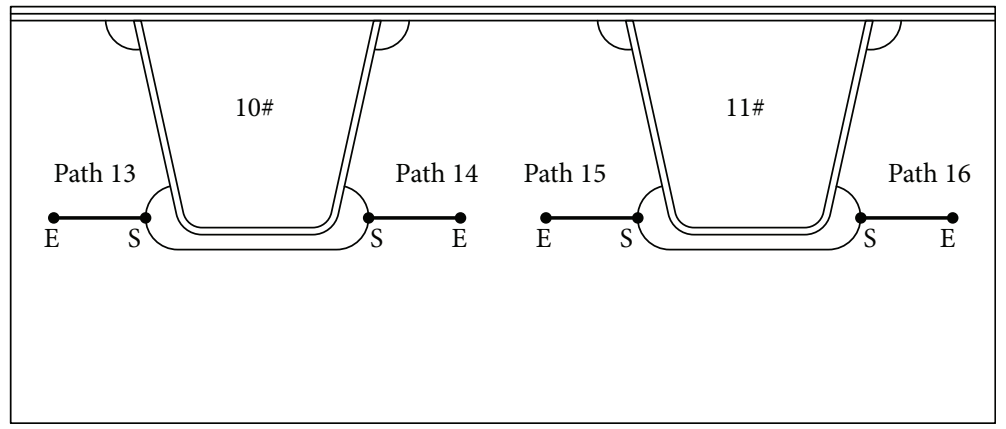

(b)

Figure 11: Stress extraction paths 5-8 and 13-16 (S: path starting; E: path ending). (a) Paths 5-8. (b) Paths 13-16.

elasticity models, only the elastic constitutive model needs to be used. Measured value was taken as the steel elastic modulus. Three-dimensional reduced-integration solid units C3D8R were used as finite element model units. Overall mesh division is shown in Figure 16(a). In order to reduce computation time, uneven mesh division could be conducted to the diaphragm. At the parts remote from joints between U-rib and diaphragm, coarse mesh processing was conducted, with mesh size of about $20 \mathrm{~mm}$. At the parts near joints of U-rib and diaphragm, where fatigue problems are prominent, mesh densification was carried out. According to demands of two fatigue assessment methods, the mesh size was refined to $1 \mathrm{~mm}$ during use of LSA, as shown in Figure 16(b); during use of TCD, meshes were refined to $0.1 \mathrm{~mm}, 0.05 \mathrm{~mm}$, and $0.02 \mathrm{~mm}$, and three models were established, as shown in Figure 16(c). In this way, effects of mesh sensitivity on analysis results of local stress could be considered. All the parts of the components were connected by TIE. The top plane of the specimen was loaded. In other words, modeling was achieved through coupling of loaded parts on the slab and reference point RP. Loads acted on RP. All the loads were automatically and uniformly distributed at loading parts.

4.2. Verification of Numerical Model. The experiment was conducted in a lab of Tianjin University. Distribution beams were used for loading in the experiment. The loading end was located at 1/10 height of the beam. One end of the beam acted on one of the two bearings of the test specimen, and the other end of the beam acted on the corresponding area of the U-rib. As the main loading end, it has actual load which was 0.9 time that of the mechanical load. Installation of experimental devices and components is shown in Figure 17. Two ends of component bottom and the experimental table were connected by hinging. Gasket was arranged on the lower part of loading end for loading. Its size is $100 \times 200 \times 50 \mathrm{~mm}$. Lateral edges of the gasket coincided with corresponding positions of the upper edge of the U-rib. Grade loading system was adopted in the experiment. One grade was defined as $25 \mathrm{kN}$. Unloading was conducted after loading value reached $300 \mathrm{kN}$. Unloading was also achieved in a grade manner. Data were collected and experimental phenomena were observed during each loading and unloading process.

Stress values and stress distribution computed by the numerical model were compared with experimental results. Hence, correctness of the numerical model could be verified. The finite element model with refined mesh size of $1 \mathrm{~mm}$ was selected for comparative analysis. On one side, the mesh size approached the size of strain gages and could reflect the average strain level in millimeter sections near measurement points; and on the other side, the mesh size was corresponding to the model with the lowest mesh density among all the refined mesh models. Rationality of the model would reflect rationality of other more refined models to a certain extent, and correctness of macroscopic boundary conditions used by the numerical computation model could be verified. This way, load-stress curves could be obtained according to experimental and numerical simulation results of measurement points, as shown in Figure 18(a). It is shown in the diagram that despite slide differences, strain in experiment and numerical simulation basically had the consistent trends. Comparison results 


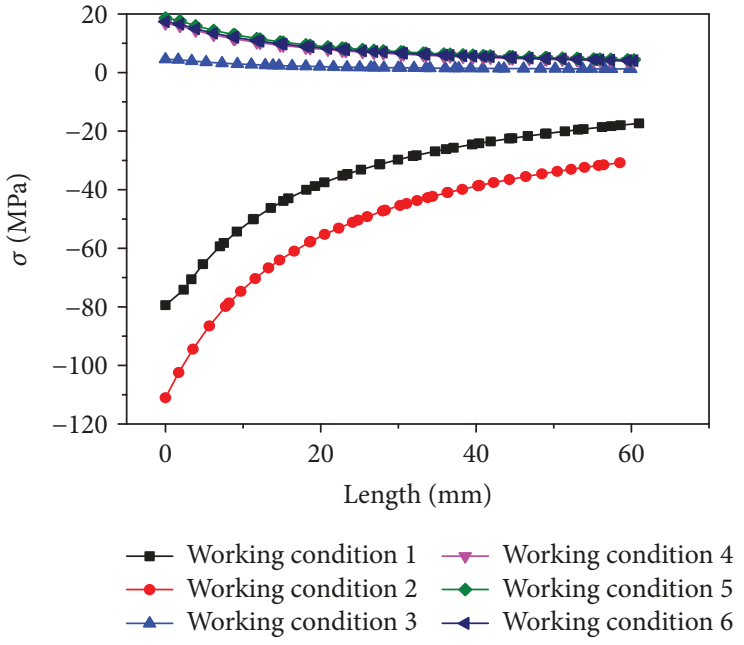

(a)

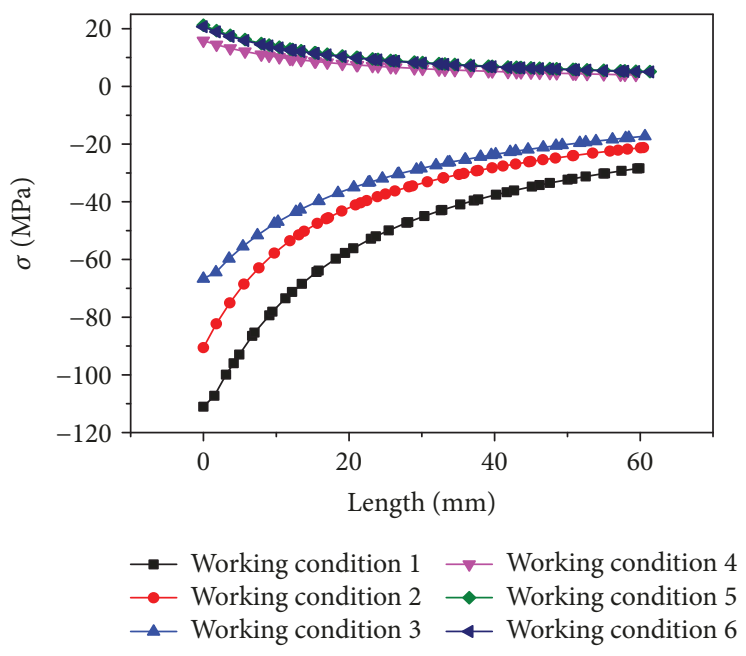

(c)

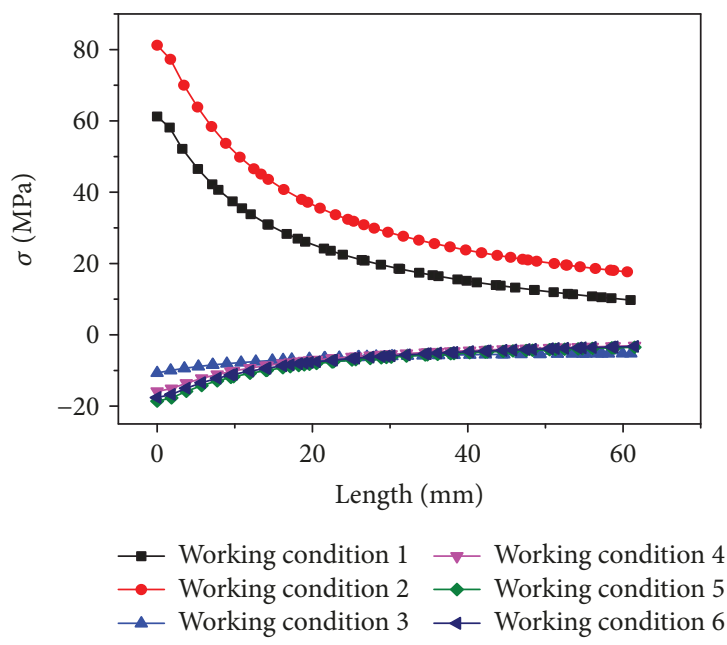

(b)

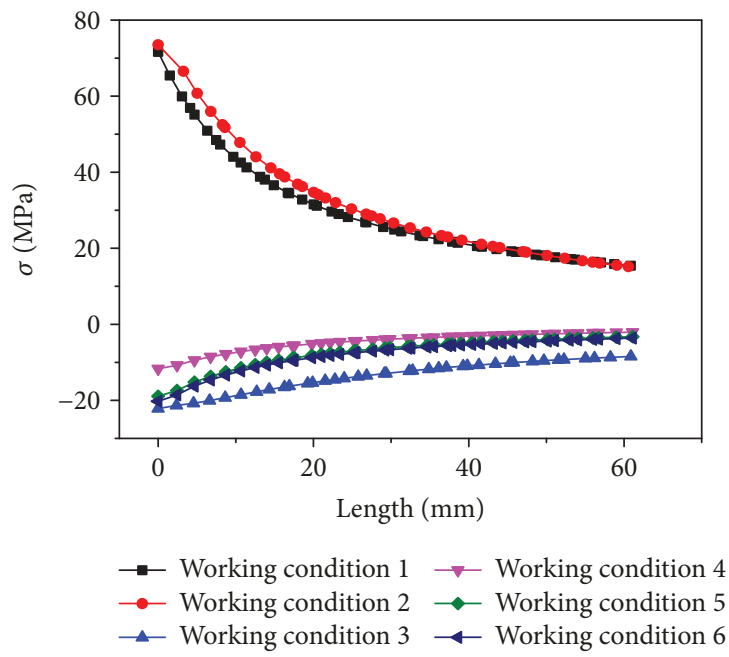

(d)

Figure 12: Stress distribution at positions with different distances from edges of cut-cuts. (a) Path 5. (b) Path 6. (c) Path 7. (d) Path 8.

show that the strain error of both was within $15 \%$. Hence, strain changes of the test specimens can be reflected basically. Figure 18(b) shows stress changes on arc edges of the diaphragm in experimental testing and numerical simulation. Obviously, measured data were distributed near the curve computed by finite numerical simulation, and angle-based stress variance trends were the same. Coincidence degree between finite element computation results and experimental testing results was high.

Finite element models were used to analyze stress distribution of the test specimens in fatigue experiment. Diagram of stress distribution at the cut-outs in diaphragms under U-ribs is shown in Figure 19(a). It is shown in the diagram that maximum stress appeared at the cut-outs in diaphragms under U-ribs. Figure 19(b) shows stress distribution at the cut-outs in the diaphragm in fatigue experiment. Comparison results show that stress distribution at the cut-outs in diaphragms under U-ribs, which was computed by the numerical models, was basically consistent with results obtained by thermal imaging. Hence, correctness of computation results of the finite element models could be verified further. Therefore, the numerical model can be used for research in the paper.

\subsection{Fatigue Life Analysis of Full-Scale Test Specimens of Orthotropic Bridge Slab}

4.3.1. Fatigue Life Assessment Based on LSA. In order to conduct full assessment of fatigue life of full-scale test specimens of the orthotropic bridge slab, three load working conditions for numerical simulation were selected. For test specimen 1, the maximum load was $45 \mathrm{t}$; for test specimen 2, the maximum load was $36 \mathrm{t}$; for test specimen 3 , the maximum load was $34 \mathrm{t}$. Principles of LSA were discussed in Section 2. As for the orthotropic bridge slab, the elastic stress concentration coefficient $K_{\mathrm{t}}$ at the cut-outs in the diaphragm under the U-rib should be acquired at first. Based on the elastic constitutive finite element model (with refined mesh size of $1 \mathrm{~mm}$ ), the stress cloud atlas of cut-out positions in the model loading area under the effect of unit pressure was obtained, as 


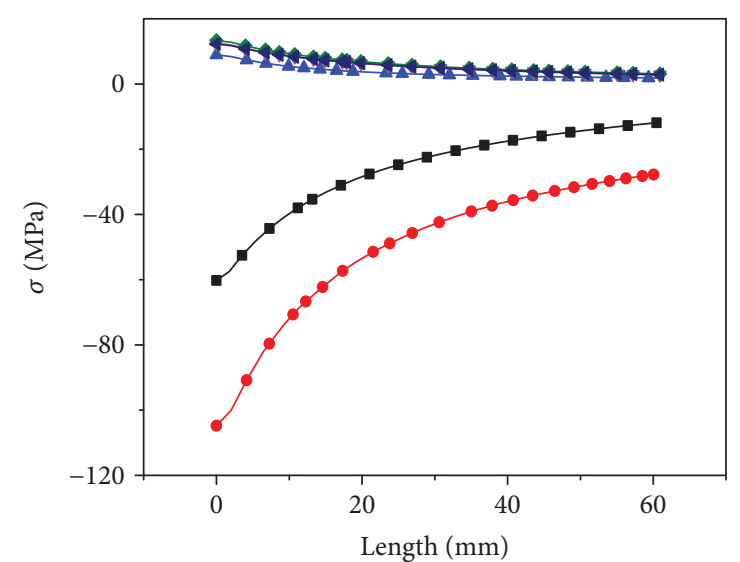

$\rightarrow$ Working condition $1 \rightarrow$ Working condition 4 $\multimap$ Working condition $2 \multimap$ Working condition 5 $\longleftarrow$ Working condition $3 \multimap$ Working condition 6

(a)

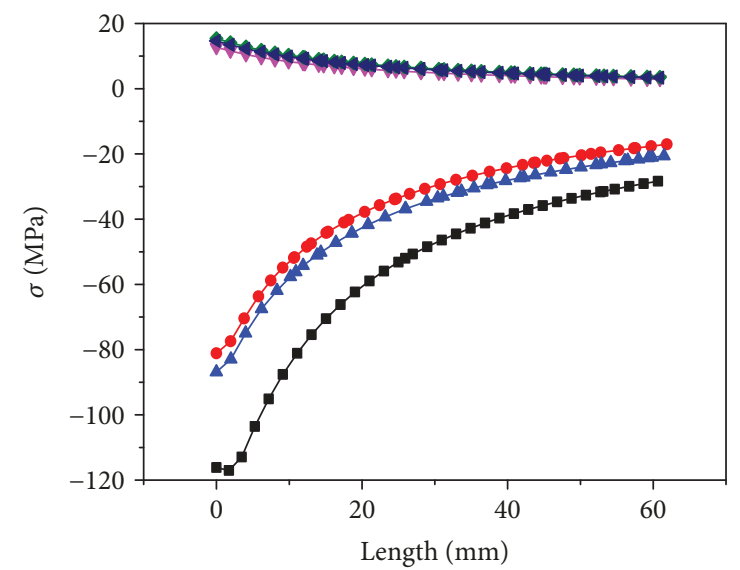

Working condition $1 \rightarrow$ Working condition 4 $\longrightarrow$ Working condition $2 \multimap$ Working condition 5 Working condition $3 \multimap$ Working condition 6

(c)

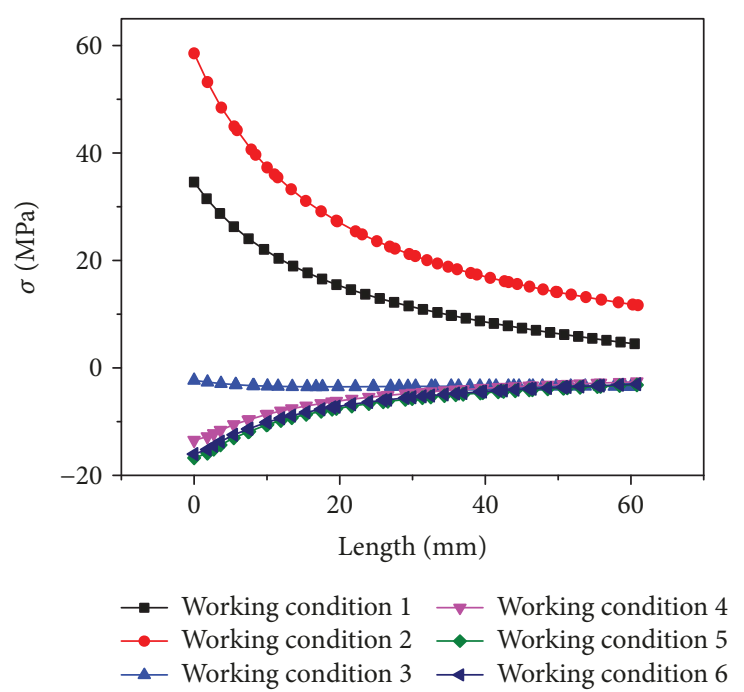

(b)

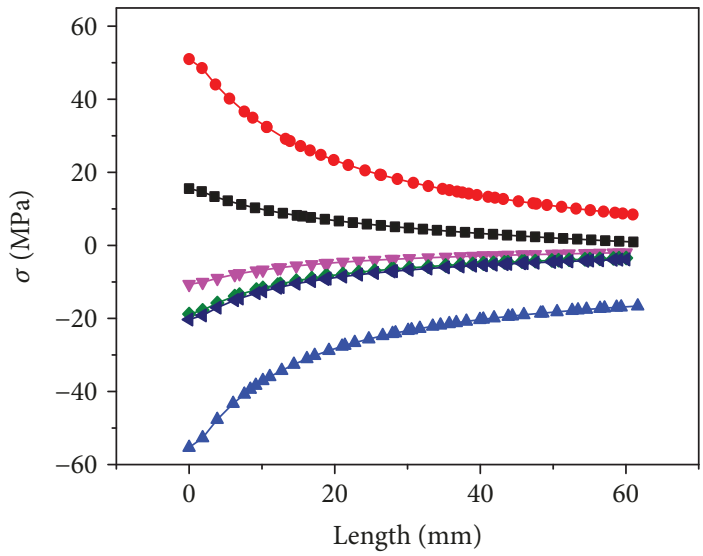

$\longrightarrow$ Working condition $1 \multimap$ Working condition 4
$\multimap$ Working condition $2 \multimap$ Working condition 5
$\longrightarrow$ Working condition $3 \multimap$ Working condition 6

(d)

FIgUre 13: Stress distribution at positions with different distances from edges of cut-outs. (a) Path 13. (b) Path 14. (c) Path 15. (d) Path 16.

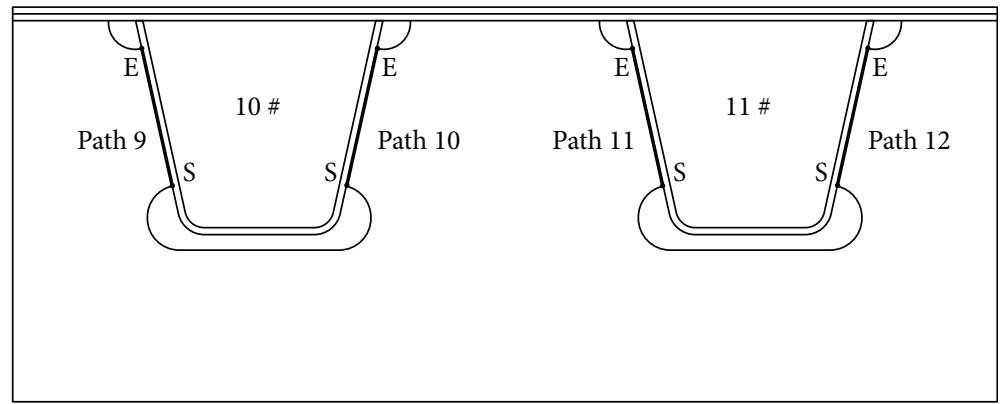

FIGURE 14: Stress extraction paths 9-12 (S: path starting; E: path ending).

shown in Figure 20. Stress values on the maximum stress path of cut-out positions were extracted. Hence, maximum stress and average stress on the path can be obtained. In this way, the elastic stress concentration coefficient of the orthotropic slab gap investigated in the paper was obtained and the value was 3.811 . 


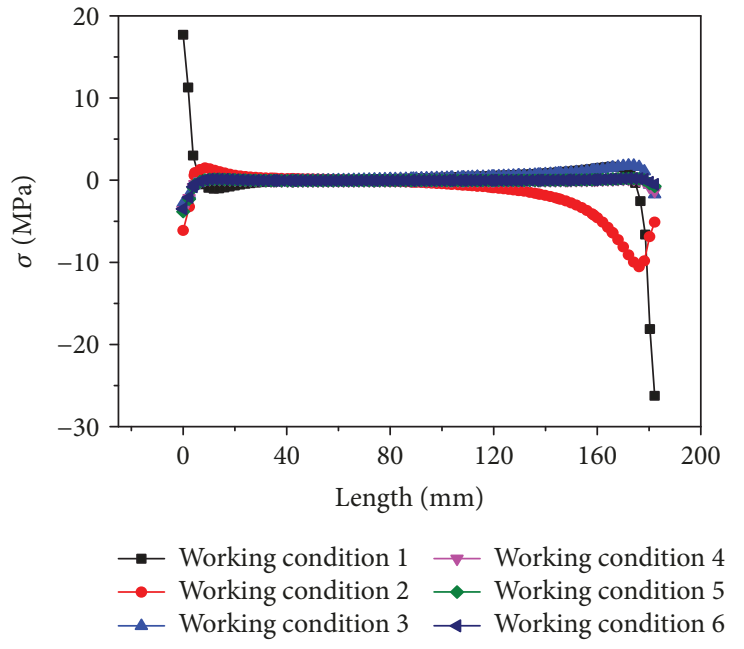

(a)

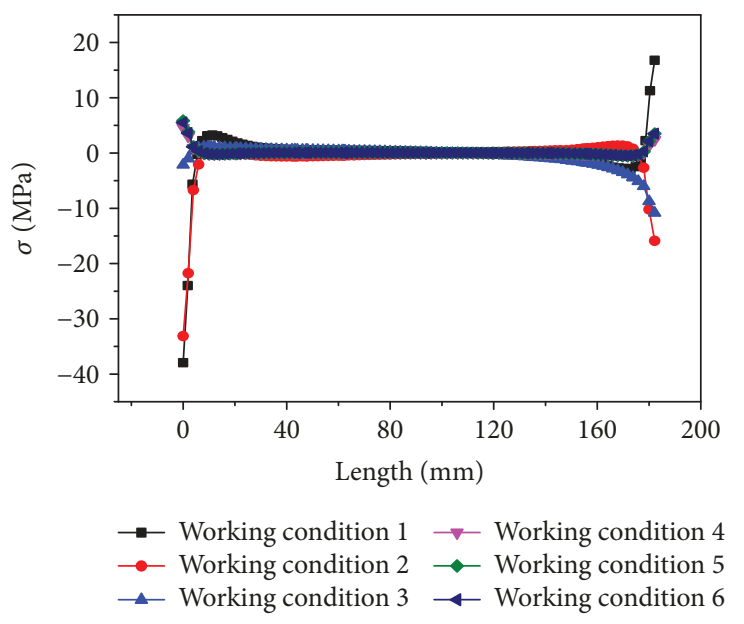

(c)

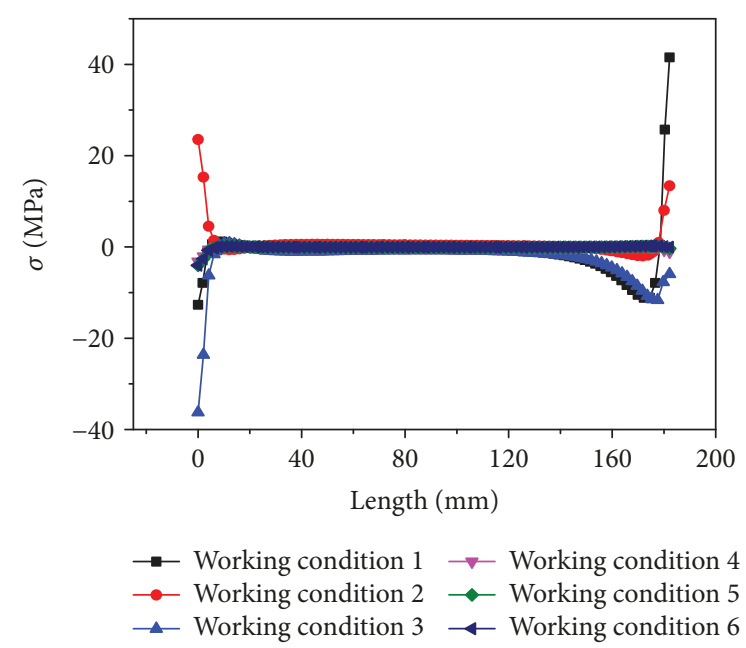

(b)

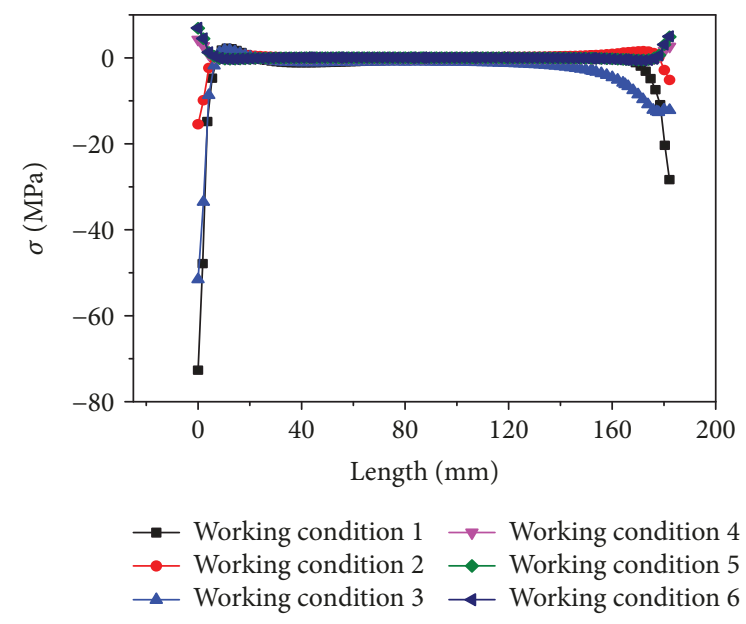

(d)

FIgURE 15: Stress distribution at welding positions of U-rib and diaphragm. (a) Path 9. (b) Path 10. (c) Path 11. (d) Path 12.

According to Formula (3),

$$
\sigma \varepsilon=K_{t}^{2} \sigma_{n} \varepsilon_{n}=3.811^{2} \sigma_{n} \varepsilon_{n}=\frac{3.811^{2} \sigma_{n}^{2}}{E} .
$$

It was found that the second stop of LSA was to determine $\sigma_{n}$ of the orthotropic bridge slab. Note that the average value of stress on the maximum stress path was taken as $\sigma_{n}$. According to the method for solving the elastic stress concentration coefficient $K_{\mathrm{t}}$, stress values on the maximum stress paths under three working conditions were extracted. The elastoplastic constitutive model should be adopted. Refined mesh size was $1 \mathrm{~mm}$. The values of $\sigma_{n}$ under each working condition were $176.53 \mathrm{MPa}, 139.93 \mathrm{MPa}$, and 131.92 MPa, respectively.

$$
\varepsilon=\frac{\sigma}{E}+\left(\frac{\sigma}{744.56}\right)^{1 / 0.1297} .
$$

Therefore, the right part of Formula (14) was a certain constant. In combination with the cyclic stress-strain curves of material (Formula (15)), values of local stress and strain under each working condition could be solved. Local strain value under each working condition was substituted into the Coffin-Manson formula. Hence, life of the test specimen under each working condition can be obtained, as shown in Table 2.

In the table, $N_{\text {LSA }}$ denotes the fatigue life predicted based on LSA and $N_{\exp }$ denotes the fatigue life corresponding to cracks of the test specimens, which was measured in the experiment. Above computation results show that the fatigue life predicted by LSA was very suitable and had very high accuracy and reliability. For test specimen 1 and test specimen 2 , the fatigue life results obtained by LSA were relatively conservative. This result is consistent with existing research conclusions.

4.3.2. Fatigue Life Assessment Based on TCD. During fatigue life assessment with TCD, relations between critical distance and designed fatigue life should be determined at first, namely the determination of Formula (11). As for Q345qD material selected in the paper, the fatigue crack expansion 


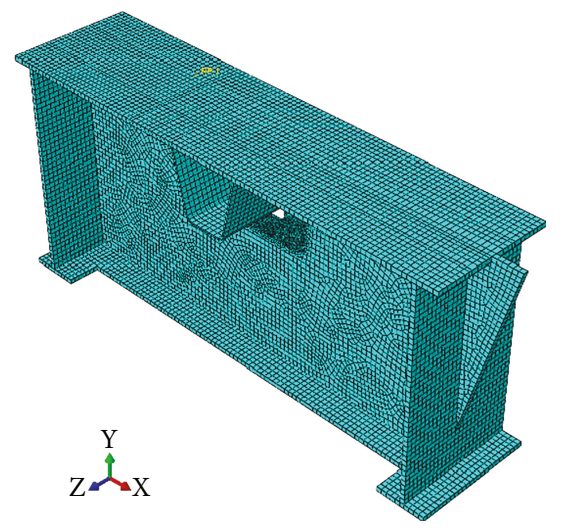

(a)

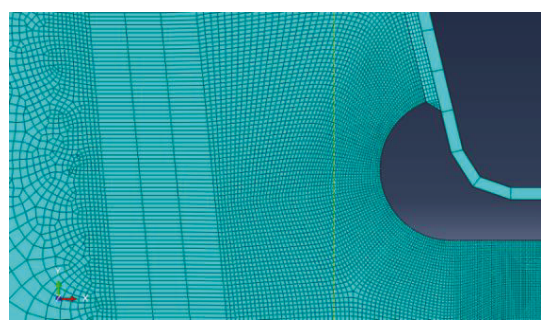

(b)

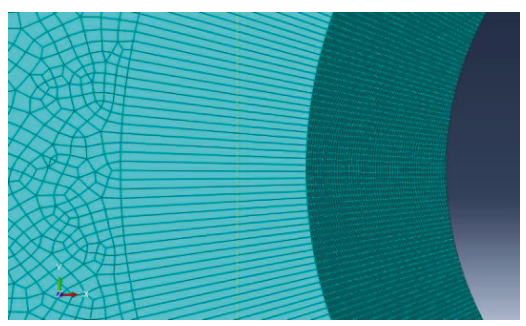

(c)

Figure 16: Computation models of U-rib and rib plate connecting diaphragm. (a) Finite element model. (b) Mesh size 1 mm. (c) Mesh size $0.1 \mathrm{~mm}$.

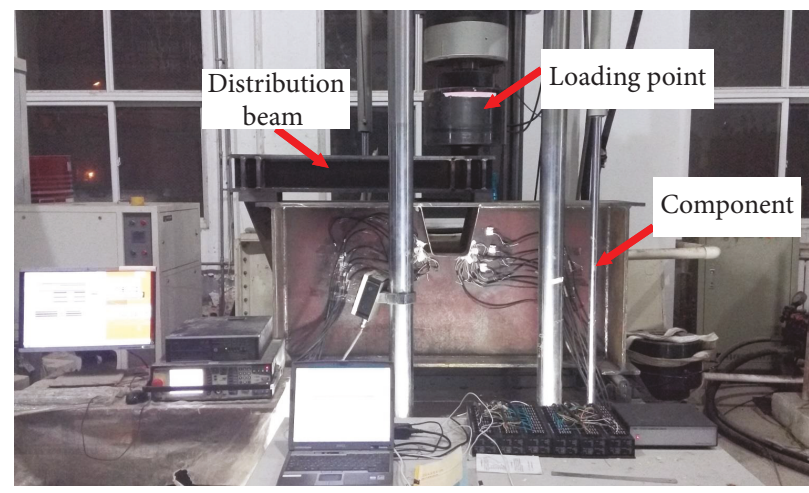

FiguRe 17: Diagram of experimental devices and components.

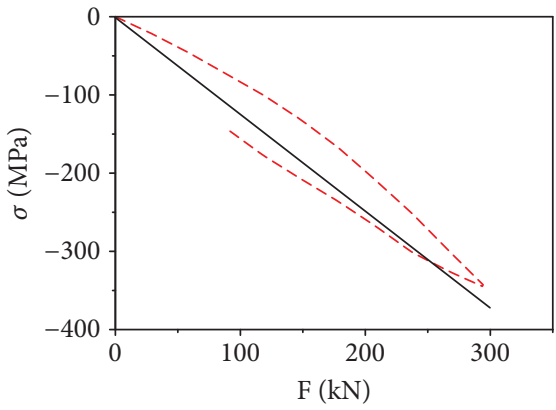

- Numerical simulation - - - Experimental testing

(a)

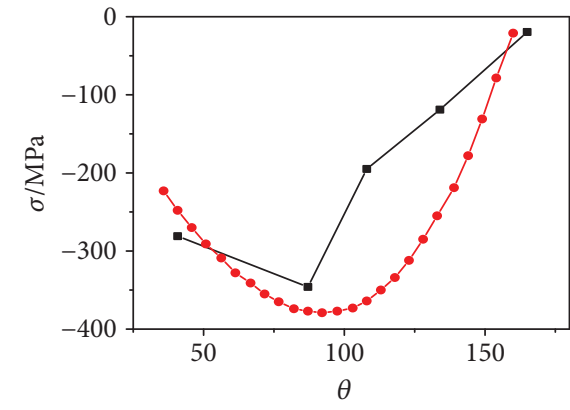

$\rightarrow$ Experimental testing $\rightarrow$ - Numerical simulation

(b)

FIGURE 18: Comparison of experimental values and numerical simulation results of stress. (a) Load-stress changing curve. (b) Stress changes on arc edges of diaphragm. 


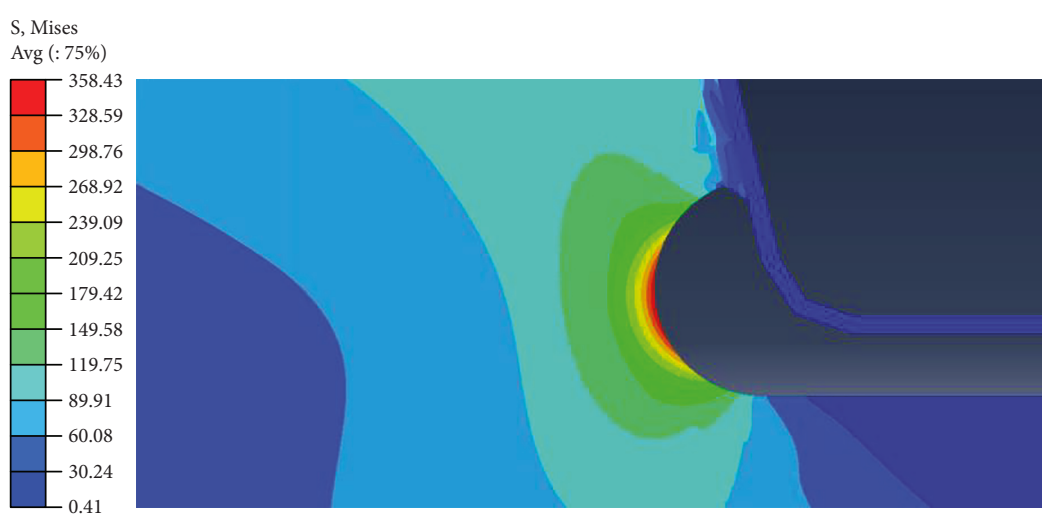

(a)

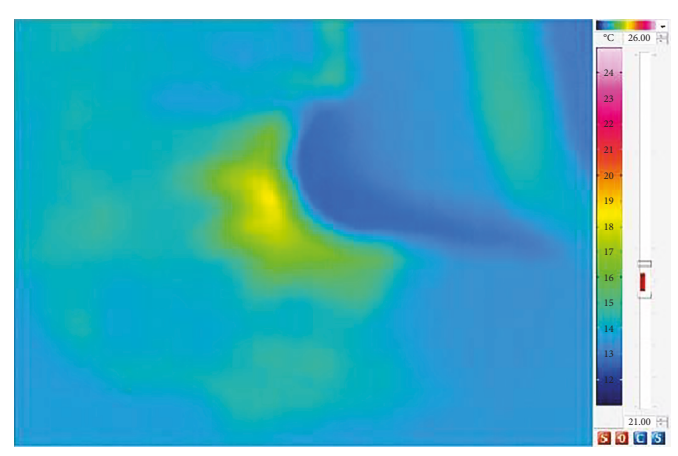

(b)

FIgURE 19: Stress distribution at the cut-outs in the diaphragm under the U-rib. (a) Numerical simulation results. (b) Experimental testing results.

threshold value was not determined in a targeted manner. In this paper, two threshold values were selected for computation: (1) According to British Norm BS7910-2005 [28], the steel universal fatigue crack expansion threshold of 2.0 $\mathrm{MPa} \cdot \mathrm{m}^{1 / 2}$ was selected; (2) according to experimental result of Q345qD welding joint material obtained by Zong et al. [29], fatigue crack expansion threshold value of $11.54 \mathrm{MPa} \cdot \mathrm{m}^{1 / 2}$ was selected. In addition, according to experimental testing results, the stress amplitude corresponding to the fatigue life $N=2 \times 10^{6}$ was determined to be $256.23 \mathrm{MPa}$. Hence, the following computation could be conducted.

$$
\begin{aligned}
& \text { When } \Delta K_{\text {th }}=2 \mathrm{MPa} \sqrt{\mathrm{m}}, L_{0 L}=A\left(2 \times 10^{6}\right)^{B} \\
& =\frac{1}{\pi}\left(\frac{\Delta K_{\mathrm{th}}}{\Delta \sigma_{\mathrm{f}}}\right)^{2}=0.0192 \mathrm{~mm} \text {, } \\
& \text { When } \Delta K_{\text {th }}=11.54 \mathrm{MPa} \sqrt{m}, L_{0 L}=A\left(2 \times 10^{6}\right)^{B} \\
& =\frac{1}{\pi}\left(\frac{\Delta K_{\mathrm{th}}}{\Delta \sigma_{\mathrm{f}}}\right)^{2}=0.646 \mathrm{~mm} \text {. }
\end{aligned}
$$

Fracture toughness $K_{\mathrm{IC}}$ of Q345 material under room temperature was $3847 \sim 4139 \mathrm{MPa} \cdot \mathrm{mm}^{1 / 2}$ [30]. The average value of this scope, namely $3993 \mathrm{MPa} \cdot \mathrm{mm}^{1 / 2}$, was selected. According to experimental testing results, limit strength of the material was $515.94 \mathrm{MPa}$. Hence, the following computation could be conducted.

$$
L_{0 \mathrm{~b}}=A\left(\frac{1}{4}\right)^{B}=\frac{1}{\pi}\left(\frac{K_{\mathrm{IC}}}{\sigma_{u}}\right)^{2}=19.07 \mathrm{~mm}
$$

Through combination of Formula 16, Formula (17), and Formula (18), it could be found that when $\Delta K_{\text {th }}=$ $2 \mathrm{MPa} \cdot \mathrm{m}^{1 / 2}, A=10.449$ and $B=-0.434$; when $\Delta K_{\mathrm{th}}=$ $11.54 \mathrm{MPa} \cdot \mathrm{m}^{1 / 2}, A=14.192$ and $B=-0.213$. Hence, the quantitative relation between critical distance and designed fatigue life can be obtained.

Next, stress-distance relations on the maximum stress path should be acquired, so equivalent stress near the gap can be solved by point method or line method. According

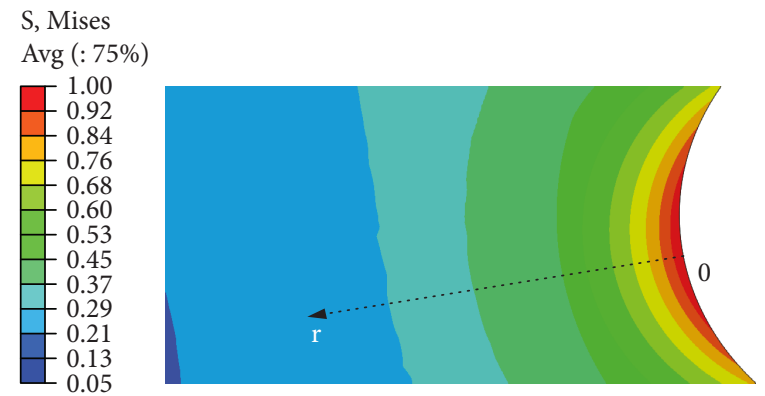

Figure 20: Cloud atlas of cut-out positions on diaphragm.

TABLE 2: Assessment results of fatigue life based on LSA.

\begin{tabular}{lccccc}
\hline Test specimen & $\sigma_{\mathrm{n}} / \mathrm{MPa}$ & $\sigma / \mathrm{MPa}$ & $\varepsilon$ & $N_{\text {LSA }}$ & $N_{\exp }$ \\
\hline 1 & 176.53 & 366.344 & 0.005997 & 5183 & 11,000 \\
2 & 139.93 & 340.517 & 0.004054 & 51,041 & 67,000 \\
3 & 131.92 & 333.739 & 0.003676 & 104,941 & 106,000 \\
\hline
\end{tabular}

to the life interval of (the) test specimens, critical distances obtained through computation were less than $5 \mathrm{~mm}$. If computation was conducted based on the refined mesh of $1 \mathrm{~mm}$ in LSA, the accurate stress-distance relations could hardly be obtained. Hence, local meshes were further refined. Mesh sizes were set as $0.1 \mathrm{~mm}, 0.05 \mathrm{~mm}$, and $0.02 \mathrm{~mm}$. On this basis, local stress cloud atlas under the working condition (load of $45 \mathrm{t}$ ) was extracted, as shown in Figure 20. According to the stress cloud atlas, stress-distance relations under each working condition can be acquired further.

Finite element computation results in Figure 21 show that with gradual refinement of mesh size, the stress level on the maximum stress path gradually tended to be stable. Finally, model computation results corresponding to the mesh size of $0.02 \mathrm{~mm}$ were selected as subsequent computation basis. For convenient subsequent computation, polynomial fitting was conducted to extracted stress-distance relations. The highest power was the quadratic square of $r$, satisfying basic rules of stress field distribution near the 


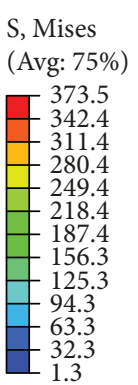

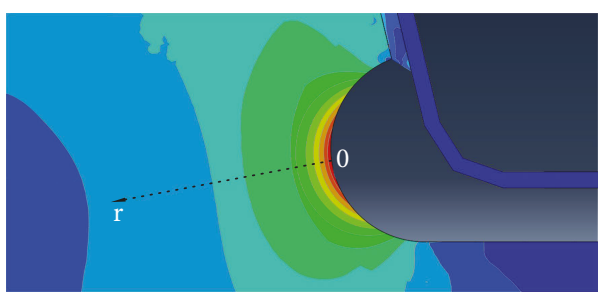

(a)
S, Mises (Avg: 75\%)

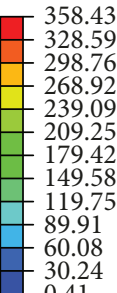

0.41

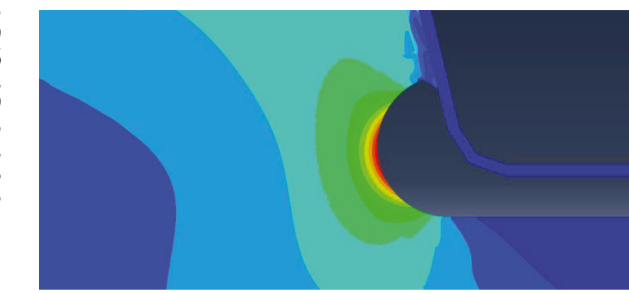

(b)

S, Mises

(Avg: 75\%)

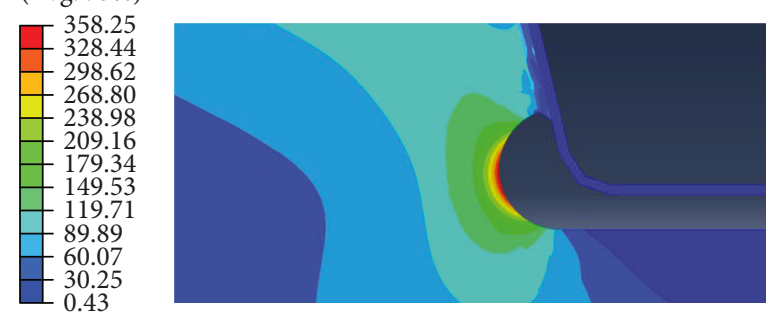

(c)

Figure 21: Cloud atlas of cut-out positions of diaphragm. (a) Local stress cloud atlas (size $=0.1 \mathrm{~mm}$ ). (b) Local stress cloud atlas $($ size $=0.05 \mathrm{~mm}) .(\mathrm{c})$ Local stress cloud atlas $($ size $=0.02 \mathrm{~mm})$.

TABLe 3: Assessment results of fatigue life based on point method.

\begin{tabular}{lcccccc}
\hline & Test specimen & $N_{\text {max }} / \mathrm{t}$ & $\sigma_{\mathrm{pm}} / \mathrm{MPa}$ & $L / \mathrm{mm}$ & $N_{\mathrm{TCD}}$ & $N_{\text {exp }}$ \\
\hline \multirow{3}{*}{$\Delta K_{\mathrm{th}}=2 \mathrm{MPa} \cdot \mathrm{m}^{1 / 2}$} & 1 & 45 & 365.60 & 0.34 & 2675 & 11,000 \\
& 2 & 36 & 294.51 & 0.11 & 35,863 & 67,000 \\
& 3 & 34 & 278.38 & 0.08 & 70,509 & 106,000 \\
\hline \multirow{2}{*}{$\Delta K_{\text {th }}=11.54 \mathrm{MPa} \cdot \mathrm{m}^{1 / 2}$} & 1 & 45 & 344.88 & 2.28 & 5389 & 11,000 \\
& 2 & 36 & 283.47 & 1.38 & 56,739 & 67,000 \\
& 3 & 34 & 269.11 & 1.21 & 105,906 & 106,000 \\
\hline
\end{tabular}

gap. Correlation coefficient of data fitting reached 0.999, indicating that the fitted $\sigma-r$ relation expression could represent real stress distribution. Life assessment was conducted with point method and line method, as follows.

Point Method (PM). PM was used for life assessment of the test specimens. Computation results corresponding to two fatigue crack expansion thresholds were obtained, as shown in Table 3. $\sigma_{\mathrm{pm}}$ was obtained based on the $\sigma-r$ relation expression with complete elastic model fitting (Formulas (6)-(9)). Obviously, with the increase of fatigue crack expansion threshold, the predicted fatigue life increased; fatigue lives of three test specimens corresponding to $\Delta K_{\mathrm{th}}=2$ $\mathrm{MPa} \cdot \mathrm{m}^{1 / 2}$ were shorter than experimental values, and the results were relatively conservative; except for test specimen 3 , fatigue lives corresponding to $\Delta K_{\text {th }}=11.54 \mathrm{MPa} \cdot \mathrm{m}^{1 / 2}$ were shorter than experimental results. As a whole, assessment results corresponding to two thresholds were consistent with experimental values in a relative order.

Line Method (LM). LM was used for life assessment of the test specimens. Computation results corresponding to two fatigue crack expansion thresholds were obtained, as shown in Table 4 . It is also obvious that, with the increase of fatigue crack expansion threshold, the predicted fatigue life increased. For test specimen 1, relatively conservative prediction results were obtained with two thresholds; for test specimen 3, relatively dangerous prediction results were obtained with two thresholds. However, in view of discreteness of fatigue test results, we must admit that assessment results corresponding to two values were consistent with experimental values in a certain order.

4.3.3. Comparison of Two Assessment Methods. Quantitative comparison of the accuracy of two assessment methods in fatigue life assessment was conducted, as shown in Table 5. Obviously, with LSA, relatively conservative assessment results of fatigue life were given as a whole; prediction results of TCD depended on input conditions and adopted methods (i.e., PM, LM, AM, and VM). The average value of ratios of predicted lives to experimental lives was taken as the measurement index. It was found that the PM assessment results corresponding to $\Delta K_{\text {th }}=11.54 \mathrm{MPa} \cdot \mathrm{m}^{1 / 2}$ and the LM assessment results corresponding to $\Delta K_{\mathrm{th}}=2 \mathrm{MPa} \cdot \mathrm{m}^{1 / 2}$ had the 
TABLE 4: Assessment results of fatigue life based on line method.

\begin{tabular}{|c|c|c|c|c|c|c|}
\hline & Specimen & $N_{\max } / \mathrm{t}$ & $\sigma_{\mathrm{lm}} / \mathrm{MPa}$ & $L / \mathrm{mm}$ & $N_{\text {TCD }}$ & $N_{\text {exp }}$ \\
\hline \multirow{3}{*}{$\Delta K_{\mathrm{th}}=2 \mathrm{MPa} \cdot \mathrm{m}^{1 / 2}$} & 1 & 45 & 349.70 & 0.27 & 4561 & 11,000 \\
\hline & 2 & 36 & 282.96 & 0.09 & 57,978 & 67,000 \\
\hline & 3 & 34 & 267.61 & 0.07 & 113,199 & 106,000 \\
\hline \multirow{3}{*}{$\Delta K_{\mathrm{th}}=11.54 \mathrm{MPa} \cdot \mathrm{m}^{1 / 2}$} & 1 & 45 & 328.28 & 2.01 & 9742 & 11,000 \\
\hline & 2 & 36 & 274.19 & 1.27 & 84,578 & 67,000 \\
\hline & 3 & 34 & 261.23 & 1.12 & 151,276 & 106,000 \\
\hline
\end{tabular}

TABLE 5: Comparison of two assessment methods.

\begin{tabular}{lcccc}
\hline Test specimen & 1 & 2 & 3 & Average \\
Experimental results & 11,000 & 67,000 & 106,000 & - \\
\hline$N_{\mathrm{LSA}} / N_{\exp }$ & 0.47 & 0.76 & 0.99 & 0.87 \\
$N_{\mathrm{pm}}, \Delta K_{\text {th }}=2 / N_{\exp }$ & 0.24 & 0.54 & 0.67 & 0.57 \\
$N_{\mathrm{pm}}, \Delta K_{\text {th }}=11.54 / N_{\exp }$ & 0.49 & 0.85 & 1.00 & 0.91 \\
$N_{\mathrm{lm}}, \Delta K_{\text {th }}=2 / N_{\exp }$ & 0.41 & 0.87 & 1.07 & 0.92 \\
$N_{\text {lm }}, \Delta K_{\text {th }}=11.54 / N_{\text {exp }}$ & 0.89 & 1.26 & 1.43 & 1.38 \\
\hline
\end{tabular}

highest accuracy, and the results were relatively conservative as a whole.

As a whole, prediction accuracies of two methods are acceptable. When computational accuracies of finite element model are similar, in comparison with LSA, TCD is an analysis method based on elastic models, whose computation cost is lower and operability is higher, and it suffers less effect from mesh size. Comparing the two TCD methods adopted in the paper, the use of PM is simpler; during computation with LM, relations between stress and distance on paths shall be determined and considered, and average computation with integration is required. Hence, for life assessment of orthotropic bridge slabs made of Q345qD, because of the lack of enough measured data of the material, the paper recommends $11.54 \mathrm{MPa} \cdot \mathrm{m}^{1 / 2}$ as the threshold and recommends PM for fatigue life assessment.

\section{Conclusions}

(1) Numerical computation results and experimental testing results had the same rules, demonstrating validly of the finite element model established in the paper. The finite element model was used to compute Mises stress distribution on diaphragm near 10\# and 11\# U-ribs under 6 working conditions. Results show that maximum Mises stress appeared at cut-outs. Stress was distributed in a multiparabolic form along the paths. Stress along the paths reached the maximum value on the edges of the cut-outs. Stress gradually attenuated with the increase of distance from the edges of the cut-outs. Attenuation was already very significant and reached about $60 \%$ when the distance was $20 \mathrm{~mm}$. With continuous increase of distance, the attenuation speed gradually decreased
(2) Prediction accuracies of two methods are acceptable. With LSA, relatively conservative assessment results of fatigue life were given as a whole. Prediction results of TCD depended on material fatigue parameters and adopted methods to a certain extent. When computational accuracies of finite element model are similar, in comparison with LSA, TCD is an analysis method based on elastic models, whose computation cost is lower and operability is higher, and it suffers less effect from mesh size

(3) TCD was used to conduct life assessment of the diaphragm of the orthotropic bridge slab. Through comparison with experimental life results, it was found that with the same analysis method, the fatigue life assessment results were relatively conservative under fatigue crack expansion thresholds of $2 \mathrm{MPa} \cdot \mathrm{m}^{1 / 2}$ and $11.54 \mathrm{MPa} \cdot \mathrm{m}^{1 / 2}$; when the same fatigue crack expansion threshold was used, the fatigue life assessment results obtained by PM were more conservative than those obtained by LM

(4) The research shows that all fatigue cracks are observed at the cut-outs in diaphragms under U-ribs. Hence, a better way of cut-outs should be adopted in actual bridges to reduce cracks

\section{Data Availability}

The data used to support the findings of this study are available from the corresponding author upon request.

\section{Conflicts of Interest}

The authors declare that there is no conflict of interests regarding the publication of this paper.

\section{References}

[1] H. Han, J. Wang, X. Meng, and H. Liu, "Analysis of the dynamic response of a long span bridge using GPS/accelerometer/anemometer under typhoon loading," Engineering Structures, vol. 122, pp. 238-250, 2016.

[2] S. Li, S. Laima, and H. Li, "Cluster analysis of winds and wind-induced vibrations on a long-span bridge based on long-term field monitoring data," Engineering Structures, vol. 138, pp. 245-259, 2017.

[3] F. Gallerano, G. Cannata, L. Barsi, and S. Scarpone, "Numerical investigation of fluid-structure interaction for long-span 
bridge decks," WIT Transactions on Engineering Sciences, vol. 105, pp. 15-26, 2016.

[4] G. D. Zhou, T. H. Yi, B. Chen, and H. Zhang, “A generalized Pareto distribution-based extreme value model of thermal gradients in a long-span bridge combining parameter updating," Advances in Structural Engineering, vol. 20, no. 2, pp. 202-213, 2017.

[5] Y. Luo, D. Yan, M. Yuan, and N. W. Lu, "Probabilistic modeling of fatigue damage in orthotropic steel bridge decks under stochastic traffic loadings," Journal of Highway and Transportation Research and Development (English Edition), vol. 11, no. 3, pp. 62-70, 2017.

[6] B. Cheng, X. Ye, X. Cao, D. D. Mbako, and Y. Cao, "Experimental study on fatigue failure of rib-to-deck welded connections in orthotropic steel bridge decks," International Journal of Fatigue, vol. 103, pp. 157-167, 2017.

[7] K. Yokozeki and C. Miki, "Fatigue evaluation for longitudinalto-transverse rib connection of orthotropic steel deck by using structural hot spot stress," Welding in the World, vol. 60, no. 1, pp. 83-92, 2016.

[8] F. Yan, Z. Lin, and Y. Huang, "Numerical simulation of fatigue behavior for cable-stayed orthotropic steel deck bridges using mixed-dimensional coupling method," KSCE Journal of Civil Engineering, vol. 21, no. 6, pp. 2338-2350, 2017.

[9] J. R. Cuninghame, "Strengthening fatigue prone details in a steel bridge deck," Fatigue of Welded Constructions, vol. 4, pp. 127-137, 1987.

[10] W. C. Jen, "Strength of steel orthotropic deck with trapezoidal shaped longitudinal stiffeners," ProQuest, vol. 2, 2006.

[11] P. A. Tsakopoulos and J. W. Fisher, "Full-scale fatigue tests of steel orthotropic decks for the Williamsburg Bridge," Journal of Bridge Engineering, vol. 8, no. 5, pp. 323-333, 2003.

[12] P. A. Tsakopoulos and J. W. Fisher, "Full-scale fatigue tests of steel orthotropic deck panel for the Bronx-Whitestone Bridge rehabilitation," Bridge Structures, vol. 1, no. 1, pp. 5566, 2005.

[13] K. Mizuguchi, K. Yamada, M. Iwasaki, and S. Inokuchi, "Rationalized steel deck structure and large model test for developing new type of structure," Japan Soceity of Civil Engineering, vol. 12, pp. 675-688, 2004.

[14] C. Miki, "Fatigue damage in orthotropic steel bridge decks and retrofit works," International Journal of Steel Structures, vol. 6, no. 4, pp. 255-267, 2006.

[15] Z. Xiao, K. Yamada, J. Inoue, and K. Yamaguchi, "Fatigue cracks in longitudinal ribs of steel orthotropic deck," International Journal of Fatigue, vol. 28, no. 4, pp. 409-416, 2006.

[16] R. C. Battista, M. S. Pfeil, and E. M. L. Carvalho, "Fatigue life estimates for a slender orthotropic steel deck," Journal of Constructional Steel Research, vol. 64, no. 1, pp. 134-143, 2008.

[17] Z. Xiao, K. Yamada, S. Ya, and X. Zhao, "Stress analyses and fatigue evaluation of rib-to-deck joints in steel orthotropic decks," International Journal of Fatigue, vol. 30, no. 8, pp. 1387-1397, 2008.

[18] M. Aygül, M. Al-Emrani, and S. Urushadze, "Modelling and fatigue life assessment of orthotropic bridge deck details using FEM," International Journal of Fatigue, vol. 40, pp. 129-142, 2012.

[19] H. B. Sim, C. M. Uang, and C. Sikorsky, "Effects of fabrication procedures on fatigue resistance of welded joints in steel orthotropic decks," Journal of Bridge Engineering, vol. 14, no. 5, pp. 366-373, 2009.
[20] H. B. Sim and C. M. Uang, "Stress analyses and parametric study on full-scale fatigue tests of rib-to-deck welded joints in steel orthotropic decks," Journal of Bridge Engineering, vol. 17, no. 5, pp. 765-773, 2012.

[21] R. J. Connor and J. W. Fisher, "Consistent approach to calculating stresses for fatigue design of welded rib-to-web connections in steel orthotropic bridge decks," Journal of Bridge Engineering, vol. 11, no. 5, pp. 517-525, 2006.

[22] K. Cui and T. T. Zhao, "Unsaturated dynamic constitutive model under cyclic loading," Cluster Computing, vol. 20, no. 4, pp. 2869-2879, 2017.

[23] Y. E. Zhou, "Assessment of bridge remaining fatigue life through field strain measurement," Journal of Bridge Engineering, vol. 11, no. 6, pp. 737-744, 2006.

[24] M. Enckell, B. Glisic, F. Myrvoll, and B. Bergstrand, "Evaluation of a large-scale bridge strain, temperature and crack monitoring with distributed fibre optic sensors," Journal of Civil Structural Health Monitoring, vol. 1, no. 1-2, pp. 37-46, 2011.

[25] K. Cui and X. Qin, "Virtual reality research of the dynamic characteristics of soft soil under metro vibration loads based on BP neural networks," Neural Computing and Applications, vol. 29, no. 5, pp. 1233-1242, 2018.

[26] A. Yang, Y. Han, Y. Pan, H. Xing, and J. Li, "Optimum surface roughness prediction for titanium alloy by adopting response surface methodology," Results in Physics, vol. 7, pp. 10461050, 2017.

[27] K. Cui, W. Yang, and H. Gou, "Experimental research and finite element analysis on the dynamic characteristics of concrete steel bridges with multi-cracks," Journal of Vibroengineering, vol. 19, no. 6, pp. 4198-4209, 2017.

[28] BSI. BS7910, Guide to Methods for Assessing the Acceptability of Flaws in Metallic Structures London, British Standard Institute, 2005.

[29] L. Zong, G. Shi, Y. Q. Wang, and X. W. Liao, "Experimental study on fatigue crack behavior of Q345qD bridge steel butt welds," Journal of Railway Science and Engineering, vol. 12, no. 1, pp. 105-112, 2015.

[30] Y. Xiong and X. X. Hu, "The effect of microstructures on fatigue crack growth in Q345 steel welded joint," Fatigue \& Fracture of Engineering Materials \& Structures, vol. 35, no. 6, pp. 500-512, 2012. 


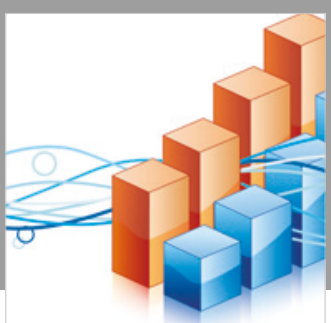

Advances in

Operations Research

\section{-n-m}
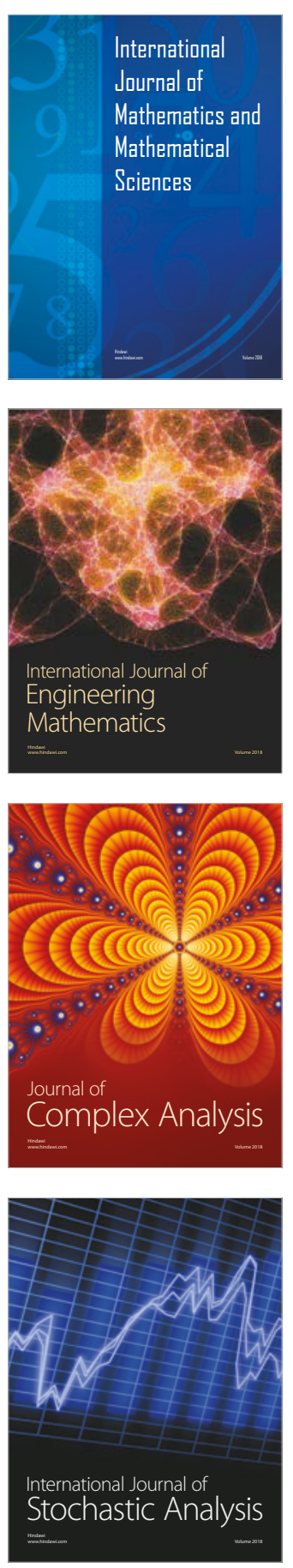
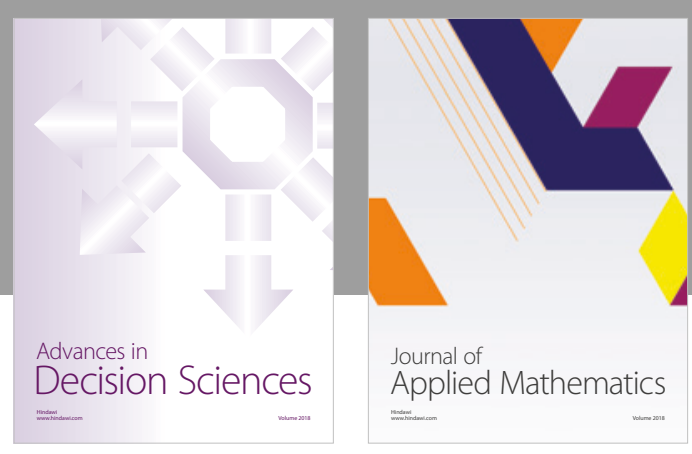

Journal of

Applied Mathematics
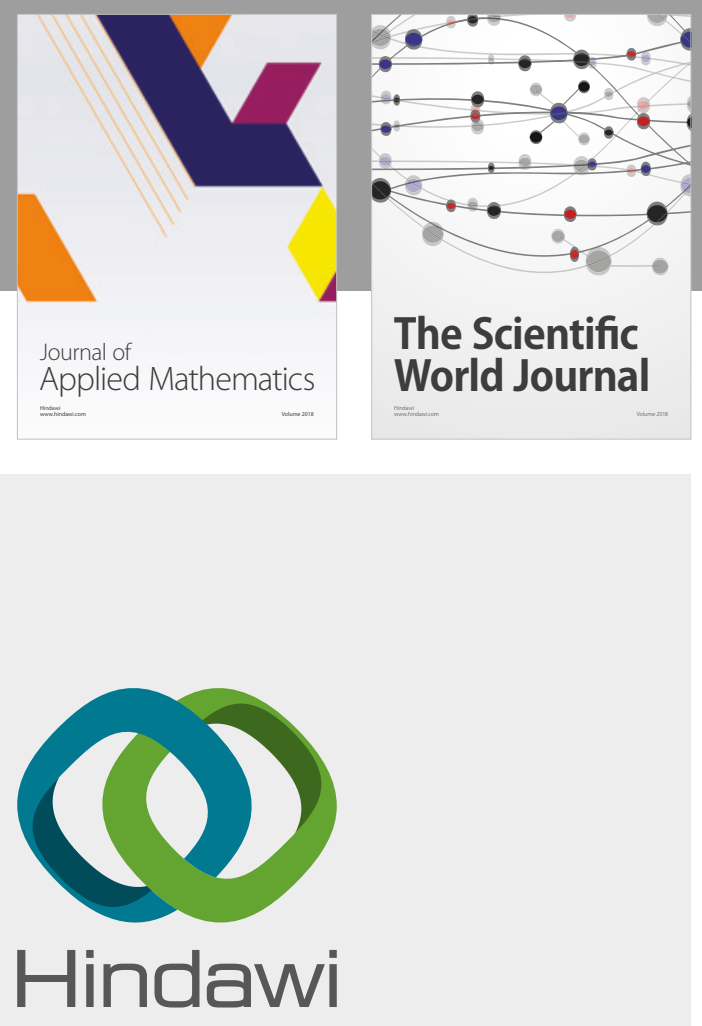

Submit your manuscripts at

www.hindawi.com

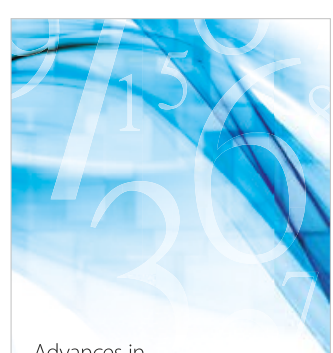

Advances in
Numerical Analysis
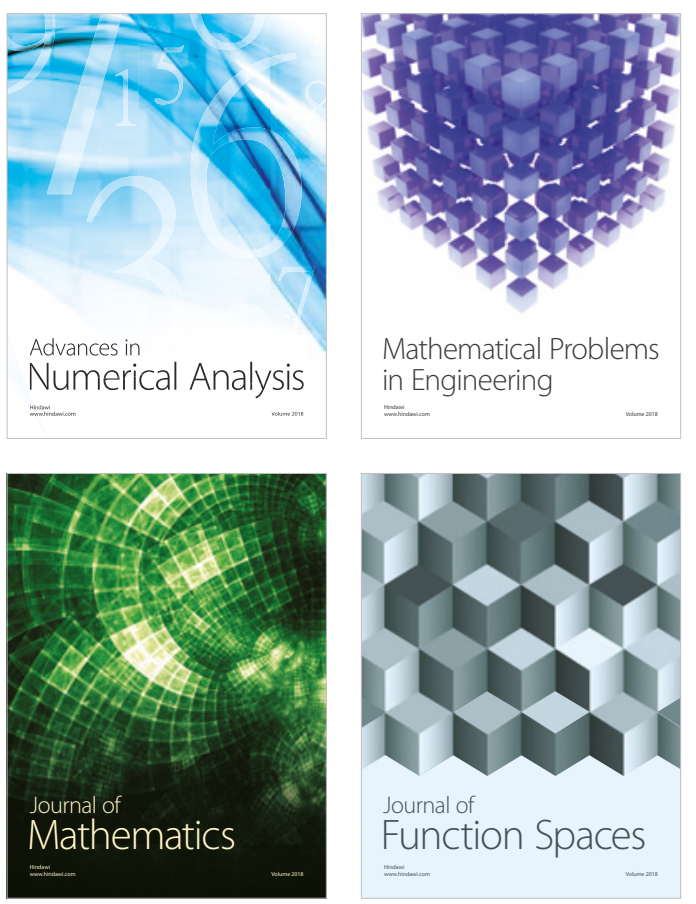

Mathematical Problems in Engineering

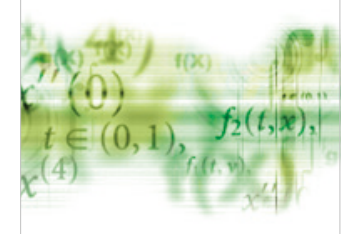

International Journal of

Differential Equations

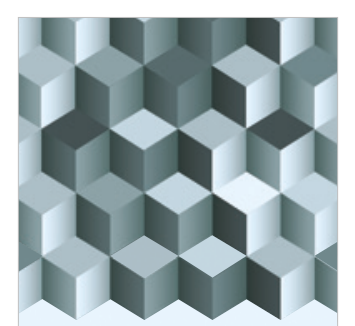

Journal of

Function Spaces
The Scientific

World Journal

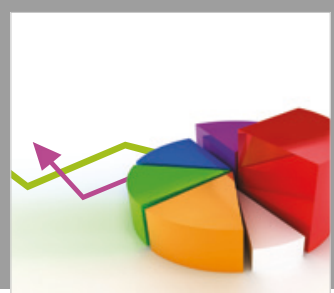

Journal of

Probability and Statistics
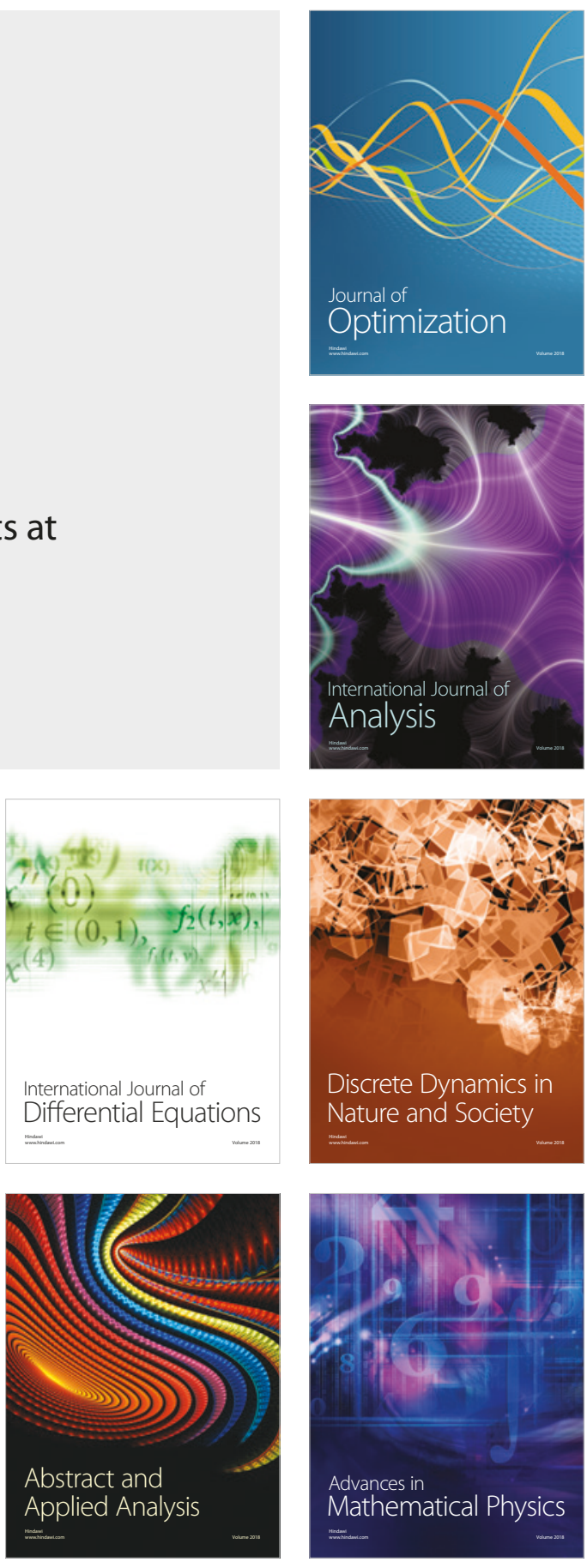